\title{
Challenges and New Advances in Ocean Color Remote Sensing of Coastal Waters
}

\author{
Hubert Loisel, Vincent Vantrepotte, \\ Cédric Jamet and Dinh Ngoc Dat
}

Additional information is available at the end of the chapter

\section{Introduction}

Knowing that coastal areas concentrate about $60 \%$ of the world's population (within $100 \mathrm{~km}$ from the coast), that $75-90 \%$ of the global sink of suspended river load takes place in coastal waters in which about $15 \%$ of the primary production occurs, the ecological, societal and economical value of these areas are obvious (fish resources, aquaculture, water quality information, recreation areas management, global carbon budget, etc). In that context, precise assessment of suspended particulate matter (SPM) concentrations and of the phenomena controlling its temporal variability is a key objective for many research fields in coastal areas. SPM which encompasses organic (living and non-living) and inorganic matter controls the penetration of light into the water and brings new nutrients into the system, both key parameters influencing phytoplankton primary production. Concentrations and availability of SPM are also known to control rates of food intake, growth and reproduction for various filter feeder organisms. Phytoplankton is highly sensitive to environmental perturbations (such as nutrient inputs, light, and turbulence). The abundance, biomass and dynamics of phytoplankton in coastal areas therefore reflect the prevailing environmental conditions and represent key parameters for assessing information on the ecological conditions, as well as on the coastal water quality. Because phytoplankton is highly sensitive to environmental perturbations [1], its distribution patterns and temporal variability represent good indicators of the ecological conditions of a defined region [2, 3]. Coastal waters also host complex ecosystems and represent important fishery areas that support industry and provide livelihood to coastal settlements. The food chain in the coastal ocean is generally short (especially in upwelling systems, having as low as three trophic levels) whereas the open ocean food web presents up to six trophic levels [4]. As a result, when compared to the open ocean, a relative lower fraction 
of the primary production gets respired in the coastal ocean while a higher fraction reaches the uppermost trophic level (fish) [5] or is exported to adjacent areas (coastal or open sea).

The potential large fluxes of carbon in the coastal ocean underscore its significance to the global carbon cycle (around 14\% of total global ocean production, along with $80-90 \%$ of new production). However, the extreme heterogeneity of coastal environments in terms of ecosystems structure and functioning, and the current large uncertainties remaining at global scale on the latter features makes difficult general assessment of net autotrophic or net heterotrophic character of these marine waters. The results of the Shelf Edge Exchange Processes Study raised the question: "Do continental shelves export organic matter?". This question still remains without any definitive answer. Bauer and Druffel [6] suggested that dissolved organic carbon (DOC) and particulate organic carbon (POC) inputs from ocean margins to the open ocean interior may be greater than inputs of recently produced organic matter derived from the open surface ocean by more than one order of magnitude. While particles from terrestrial origin are primarily deposited in the coastal region, DOC is considered as the main path for transporting terrestrial and phytoplankton derived carbon into the deep ocean [7]. The accurate assessment of the temporal variability of SPM, POC, DOC, and Chl in coastal areas over long time periods and along with physical forcing parameters may therefore provide valuable insights for improving our knowledge on the biogeochemical cycle prevailing in coastal ecosystems.

Due to the high variability of the physical and biogeochemical processes occurring in coastal areas, traditional approaches based on oceanographic cruises and in situ time series, although essential, are very time-consuming, expensive and sometimes uncertain to yield meaningful results on the studied phenomena, especially at a large synoptic scale. In this context, remote sensing of biological and physical parameters is a very powerful tool for performing large scale studies. Satellite data are not as accurate as in situ measurements and are limited to the surface layer. However, the latter limitations are largely compensated by the spatial and temporal coverage offered by the satellite observations. In situ data remain obviously necessary to validate the satellite products, in terms of absolute value, but also in terms of temporal variability in areas where long in situ time series are available. After a short introduction of the main and critical aspects of ocean color radiometry, the specific issues relative to the satellite observation of ocean color in complex natural systems such as coastal marine waters will be specifically addressed. Illustrations of current algorithms development will be then provided as well as examples of the different end-users products currently available from ocean color remote sensing in coastal waters. At last, the new challenges and concepts allowing for a better observation of coastal ecosystems from satellite ocean color observation will be discussed.

\section{General concepts of the ocean color radiometry}

The interaction of light field within the visible part of the spectrum (i.e. 400-700 nm) with the different optically significant constituents of sea water (water molecules, salt, particulate and organic dissolved matters) modifies the color of the water. These spectral variations, which 
bring qualitative and quantitative information about the water constituents, can be recorded by a passive radiometric sensor onboard a satellite platform. However, the conversion of the radiometric signal measured by the sensor at the top of the atmosphere (TOA) to the end-user parameters is not straightforward. The contribution of the reflected photons at the air-sea interface as well as the contribution of the atmosphere should first be removed from the top of atmosphere measured signal to assess the water-leaving radiance, $L_{w}(\lambda)$, which is the only radiometric parameter encompassing useful information on the water masses composition ( $\lambda$ represents the wavelength of light in nanometer, $\mathrm{nm}$ ). The removal of the atmospheric path radiance represents the most challenging part of the ocean color atmospheric correction procedure [8]. This signal, which includes Rayleigh and aerosols components, can contribute to up to $90 \%$ of the TOA signal depending on $\lambda$, the geometry of illumination and observation, the aerosol optical thickness, and the water leaving signal [9]. The importance of the latter task is particularly crucial when considering the level of accuracy required for being able to derive accurate estimates of the desired water components from $L_{w}(\lambda)$. As a matter of fact, the radiometric accuracy required for the Sea-viewing Wide Field-of-view Sensor (SeaWiFS) is, for instance, of $5 \%$ for the visible spectral domain for absolute radiance values, and of $2 \%$ for relative values (i.e. reflectances) [10].

The retrieval of the different inherent optical properties (IOPs) and biogeochemical components of the water from the water-leaving radiance spectral values are performed through biooptical algorithms. Considering that about $90 \%$ of the $L_{w}(\lambda)$ signal originates from the upper layer of the water column (the so-called first attenuation layer), the various biogeochemical or optical variables which can be retrieved from $L_{w}(\lambda)$ are assumed to be weighted averaged parameters within this upper layer [11]. The thickness of this oceanic layer in the visible part of the spectrum typically varies from less than one meter (as in turbid waters, or in the red part of the spectrum) to about 60 meters (as for oligotrophic waters in the green), depending the amount of optically significant constituents within the water mass and the measured light wavelength [12]. Since the proof-of-concept Coastal Zone Color Sensor (CZCS) mission in 1978, satellite-derived ocean color has been routinely interpreted, with increasing accuracy, in terms of upper-ocean chlorophyll concentration, Chl [13]. The great availability of ocean color satellite data, as well as the need of complementary product (additionally to $\mathrm{Chl}$ ) for validating global ocean biogeochemical models have greatly stimulated the rapid development of numerous inverse methods over the last decade for retrieving a large variety of information (Figure 1). For instance, empirical [14] and semi-analytical methods [15, 16] have been developed for specifically assessing the particulate organic carbon (POC) over the global ocean. In the same way, the various inherent optical properties are now routinely retrieved from space [17]. Among these different IOPs one may cite the coefficients of absorption by phytoplankton $\left(a_{p h y}\right)$ and colored detrital matter $\left(a_{c d m}\right)$, as well as the particulate backscattering coefficient $\left(b_{b p}\right)$. The spectral shape of $b_{b p}$ [18] and $a_{c d o m}$ [19], which, respectively, provide relevant information on the particulate and dissolved pools, are also currently accessible over open ocean waters. Note that the retrieval of the bio-optical parameters can also be performed simultaneously to the atmospheric corrections using, for instance, neural network approaches [20]. Additionally, information about phytoplankton community composition [21-23] and size distribution of marine particles [24], essential for a better understanding of the oceanic carbon cycle, are also 
available from satellite imagery. With the ability to measure the Sun-stimulated phytoplankton Chl fluorescence, information on the physiological state of algal populations could also be derived from space as illustrated from the Moderate Resolution Imaging Spectroradiometer (MODIS) and MEdium Resolution Imaging Spectrometer (MERIS) ocean color missions. Detailed description of the different atmospheric and bio-optical algorithms for the observation of ocean color from space can be found in the extensive literature provided in the International Ocean Colour Coordinating Group web site [25].
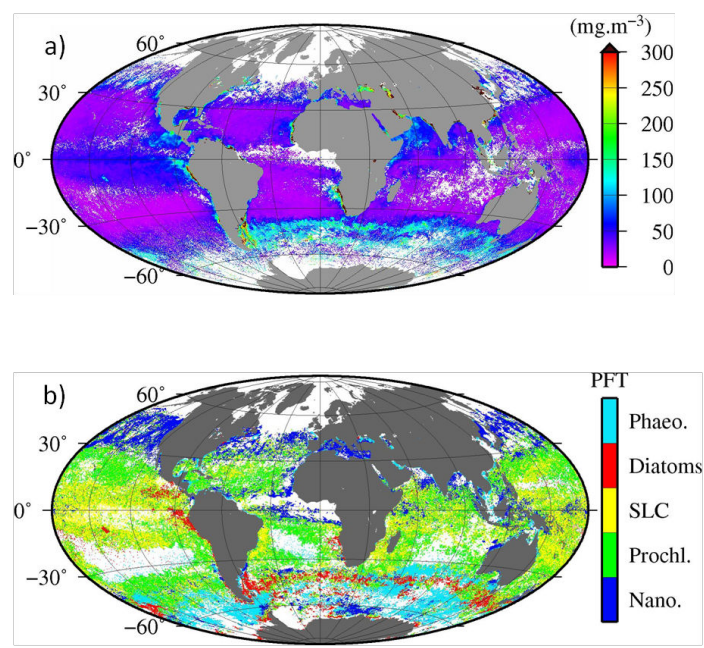

Figure 1. SeaWiFS global distribution of particulate organic carbon (a) and phytoplankton groups (b) in January 2001 as estimated by [15] and [26], respectively.

Thanks to its continuous recording of 13-years of data, the Sea-viewing Wide Field-of-viewSensor ocean color mission (SeaWiFS) has allowed great scientific advances in our understanding of the open ocean biological productivity [13]. In contrast, while ocean color observations allowed the achievement of numerous researches and new discoveries over open ocean waters, the algorithm development over coastal waters is still not mature enough to be applied routinely as it is currently performed for offshore waters, despites numerous recent advances. Some of the most important challenges remaining for developing accurate ocean color products in coastal waters are described in the following sections.

\section{Challenges to overcome for ocean color radiometry in coastal areas}

Remote sensing of ocean color in coastal areas is impacted by their intrinsic environmental features: vicinity of land over which photons can be reflected back to the sensor (the so-called adjacency effects), land inputs from rivers discharges and coastal washing, shallow waters which promote resuspension of the unconsolidated sediments as well as bottom reflected 


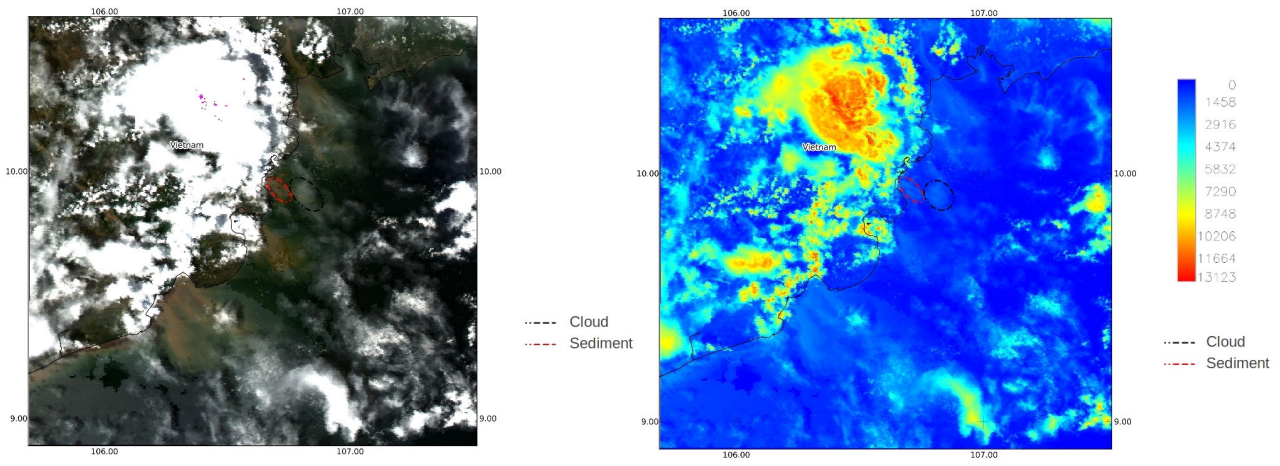

Figure 2. left) RGB composite of a daily MODIS image over the northen Vietnam coastal waters. (right) Top of atmosphere signal (in numerical counts). This figure shows that sediment dominated waters and clouds may have the same radiometric signature at the top of the atmosphere.

photons captured by the sensor in clear shallow waters, breaking waves which generate bubbles, etc. All these phenomena make difficult and challenging the assessment of bio-optical marine components from space by ocean color sensors.

The main problems to overcome in order to derive accurate observations of coastal areas from ocean colour remote sensing are associated with the presence of highly diffusing suspended mineral particles as well as high concentrations of particulate organic matter (phytoplankton, detritus) which may bias atmospheric corrections and impact bio-optical algorithms [17, 27]. Another issue largely encountered for the exploitation of ocean colour data in coastal areas is the presence of clouds. In presence of highly turbid waters, cloud-free pixels are sometimes erroneously classed as clouds, leading to a loss of data. At last, but not least, crucial and mandatory validation exercises are greatly complicated to perform due to the extreme spatial heterogeneity of these areas. These different issues will be addressed in the following sections.

\subsection{Cloud masking}

Ocean color retrieval by satellite borne sensors is in principle only possible for a clear (cloud free) atmosphere, and cloud-contaminated pixels have to be removed from the images before any ocean color processing takes place. The cloud masks developed in the frame of ocean color missions are based on the assumption that the marine reflectance in the near-infrared (NIR) is equal or close to zero. While open ocean waters can effectively be considered as black in the NIR, except in presence of highly scattered material (due for instance to offshore river plumes, or coccolithophore blooms), this is not the case for coastal waters. Indeed, the level of signal observed at the top of the atmosphere over clouds and coastal areas may be similar due to the presence of suspended sediments in the water surface (Figure 2). Cloud-free pixels are then sometimes classed as clouds and excluded from further processing, leading to a loss of data in these areas. Specific cloud masking algorithms have to then be developed over coastal waters. 


\subsection{Atmospheric corrections}

a. General description of the atmospheric correction

The use of satellites to monitor the color of the ocean requires effective removal of the contribution of the atmosphere (due to absorption by gasses and aerosols, and scattering by air molecules and aerosols) to the total signal measured by the remote sensor at the top of the atmosphere, $L_{t o a}$ : the so called "atmospheric correction" process. As shown in Figure 3, the signal measured by the remote sensor is the sum of different components. The top-ofatmosphere radiance, $L_{\text {toor }}$ can be expressed as [8]:

$$
L_{\text {toa }}(\lambda)=L_{r}(\lambda)+L_{r a}(\lambda)+L_{a}(\lambda)+t(\lambda) x L_{w c}(\lambda)+T(\lambda) x L_{g}(\lambda)+t_{0}(\lambda) x L_{w}(\lambda)
$$

where $L_{r}$ is the radiance due to the scattering of the air molecules (Rayleigh scattering), $L_{r a}$ is the multiple interaction term between molecules and aerosols, $L_{a}$ the radiance due to the scattering by aerosols, $L_{w c}$ the radiance due to the whitecaps on the sea surface, and $L_{g}$ the specular reflection of direct sunlight off the sea surface. $t(\lambda)$ and $t_{0}(\lambda)$ are the diffuse transmittances of the atmosphere from the sun to the surface and from the surface to the sensor, respectively, $T(\lambda)$ is the direct transmittance from the surface to the sensor, and $L_{w}(\lambda)$ the waterleaving radiance [28].

The terms $L_{w c} L_{g^{\prime}}$ and $L_{r}$ can be determined during a pre-processing. So the atmospheric correction algorithm needs to solve the following equation:

$$
L_{c o r}(\lambda)=L_{t o a}-L_{r}(\lambda)-t(\lambda) x \rho_{w c}(\lambda)-T(\lambda) x \rho_{g}(\lambda)=L_{a}(\lambda)+L_{r a}(\lambda)+t(\lambda) x L_{w}(\lambda)=L_{A}(\lambda)+t_{0}(\lambda) x L_{w}(\lambda)
$$

The goal of the atmospheric correction process is to accurately determine $L_{w}(\lambda)$ from the spectral measurements of $L_{c o r}(\lambda)$. For that purpose $L_{A}(\lambda)$ has to be quantified.

The classic methods for removing the contribution of the atmosphere to the total measured signal exploit the high absorption by seawater in the red and near-infrared (NIR) spectral regions. In open seawater, i.e. where generally chlorophyll-a concentration and related pigments and co-varying materials (like detritus) determine the optical properties of the ocean, seawater can be considered to absorb all light in the NIR so that the signal observed by the satellite sensor in this spectral domain is assumed to be entirely due to the atmospheric path radiance $\left(L_{A}\right)$ and sea surface reflectance [8]. This is not always the case when considering turbid waters (generally coastal optically complex waters). In these waters phytoplankton pigment and detritus, as well as suspended sediment, contribute to NIR backscatter. The resulting NIR water-leaving radiances introduce two sources of error into the standard procedure to remove the aerosols. First, the total aerosol reflectance is overestimated as some of the total radiance $\left(L_{t o a}\right)$ at two NIR bands $\left(\lambda_{1}\right.$ and $\left.\lambda_{2}\right)$ comes from the seawater. Second, as the absorption and scattering properties of seawater change from $\lambda_{1}$ to $\lambda_{2}$, the selection of the appropriate atmospheric model is affected, causing an error in the extrapolation of $L_{A}$ toward shorter wavelengths. As a result, $L_{A}$ is overestimated at all bands with increasing values at 


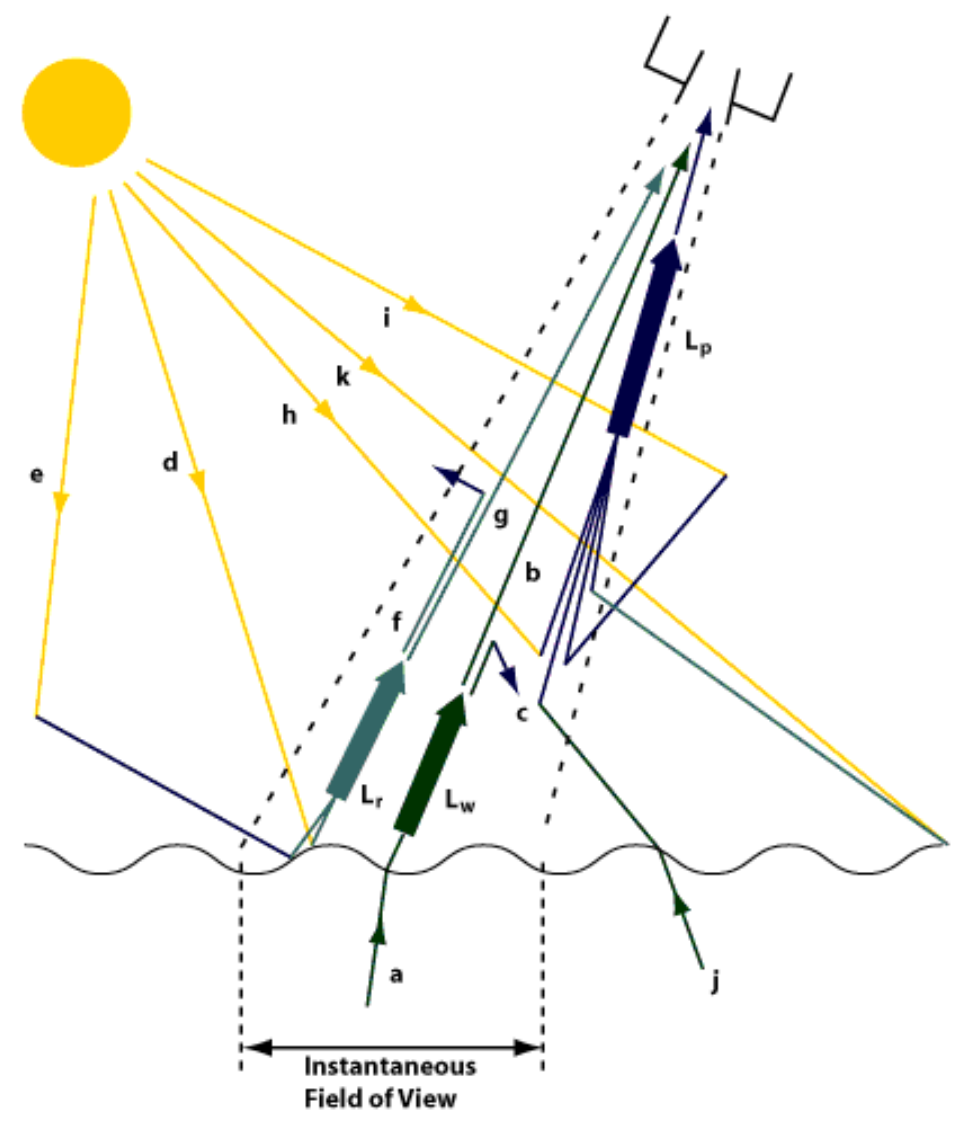

Figure 3. Illustration of several different light pathways in the atmosphere: a) The light path of the water-leaving radiance, b) the attenuation of the water-leaving radiance, c) scattering of the water-leaving radiance out of the sensor's field of view (FOV), d) sun glint (reflection from the water surface), e) sky glint (scattered light reflecting from the surface), f) scattering of reflected light out of the sensor's FOV, g) reflected light is also attenuated towards the sensor, $h$ ) scattered light from the sun which is directed toward the sensor, i) light which has already been scattered by the atmosphere which is then scattered toward the sensor, j) water-leaving radiance originating out of the sensor FOV, but scattered toward the sensor, k) surface reflection out of the sensor FOV which is then scattered toward the sensor. $L_{w}$ Total water-leaving radiance. $L_{r}$ Radiance above the sea surface due to all surface reflection effects within the FOV. $L_{p}$ Atmospheric path radiance. This Figure is adapted from [29].

shorter wavelengths, even possibly leading to negative water-leaving radiances in the blue bands [30].

The difficulty of the atmospheric correction is that the atmosphere contributes to $80-90 \%$ of the total top-of-atmosphere signal at the blue-green wavelengths $(400-550 \mathrm{~nm})$ and the atmospheric path radiance $L_{A}$ significantly varies and cannot be easily approximated. Moreover, the assumption of having a non-zero $L_{w}$ in the NIR bands is not valid for turbid waters 
(Figure 4). To solve this problem, several specific atmospheric correction algorithms have been developed in the past decade for the major past and current ocean color remote sensors [31-46].

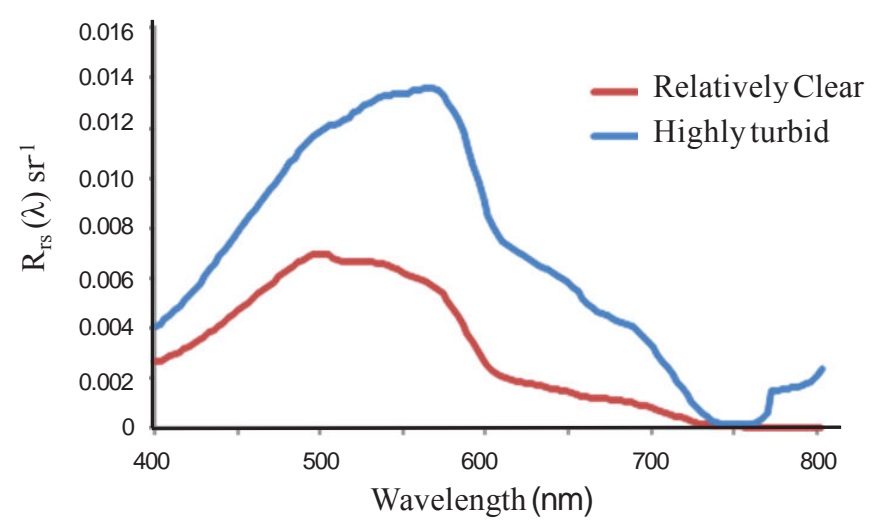

Figure 4. Spectral remote-sensing reflectance measured in relatively clear (red line), and turbid (blue line) waters of the French Guyana.

\section{Description of existing algorithms}

The algorithms previously cited can be grouped into four different categories:

\section{Assignment of hypothesis on the NIR aerosols or water contributions}

For these algorithms, assumptions are made on the aerosol models and/or the bio-optical models. Hu et al. [35] estimate the aerosol model in clear waters on the studied image and extrapolate this information over the coastal waters of the image. Ruddick et al. [40] impose a constant value of the ratio of $L_{A}$ and $L_{w}$ in the NIR. The aerosol constant NIR ratio value is determined for each image of interest taking into account only the clear waters as in [35]. The constant $L_{w}(\mathrm{NIR})$ ratio is defined from radiative transfer modeling and is assumed to be constant for any location for a given satellite sensor. This ratio is valid for low and moderate turbid waters. Using other wavelengths (SWIR, see next subsection), Wang et al. [46] developed a similar scheme than the one proposed by [35] for the Lake Taihu (China). The aerosol properties are obtained at the pixel-by-pixel level. The derived aerosol model is averaged in the middle of the lake, where the waters are not turbid. Using this mean aerosol model, the SWIR atmospheric correction algorithm use a single SWIR band and can be carried out for the entire lake for estimating $L_{w}$. These assumptions allow to use the scheme defined in [8] for the dark pixel hypothesis. These constant ratios only allow to determine $L_{A}(\mathrm{NIR})$ and to remove this contribution to $L_{c o r}$. 
2. Use of the shortwave infrared bands

For moderate and very turbid waters, it is possible to use the shortwave infrared bands (from the MODIS-AQUA sensor). The principle of this type of algorithm is very similar than the one of Gordon and Wang [8], except that the aerosols models are determined for wavelengths between 1200 and $2100 \mathrm{~nm}$ instead of NIR wavelengths. For this wavelengths range, $L_{w}$ can be considered negligible and the dark pixel atmospheric correction processing can be applied.

The difficulty with SWIR algorithms is the low signal to noise ratio for the SWIR bands of the MODIS-AQUA sensor. The algorithm shows limitations for low and moderate turbid waters, and therefore needs to be coupled with a NIR atmospheric correction algorithm [47]. More specifically, the latter authors have proposed to use the standard NIR-based atmospheric correction unless a turbidity index [48] exceeds a predefined threshold and, thereby, triggers the use of a SWIR-based correction where two SWIR bands are used instead of two NIR bands. The relevant MODIS-Aqua SWIR band pair is 1240 and $2130 \mathrm{~nm}$. Shi and Wang [48] concluded that these bands satisfy the black pixel assumption in moderately $(1240 \mathrm{~nm})$ to extremely $(2130$ $\mathrm{nm}$ ) turbid waters. This combined "NIR-SWIR" atmospheric correction approach has been evaluated extensively in several geographic locations [34, 47, 48] and validated against an independent, globally-distributed in situ data set [45]. Moreover, the difficulty of using the SWIR bands relies on the selection of the aerosol model. Analysis of the Ångström exponent retrievals suggests that the SWIR approach cannot retrieve the correct aerosol spectral dependence when the atmospheric path radiance is low. The latter feature tends to produce spectrally flat models, thus underestimating the aerosol reflectance in the shorter wavelengths. In fact, at low signals the SWIR approach often predicts aerosol spectral dependence that is beyond the range of the current aerosol models, as it would be associated with unrealistically large aerosol size distributions. Conversely, the SWIR approach tends to overestimate aerosol reflectance at higher aerosol loads, thus resulting in negative $L_{w}(\lambda)$ [49].

\section{Correction/modelling of the non-negligible $L_{\mathrm{w}}(\mathrm{NIR})$}

This type of algorithm aims to correct the non-negligible $L_{w}(\mathrm{NIR})$ signal using iterative methods coupled with a bio-optical algorithm [30, 31, 38, 43, 46]. These algorithms need to define a first value of $L_{w}$ (NIR) which can be directly fixed, or calculated from a first guess of Chl or IOPs. This can be done by using either default values of the parameters or a dark pixel atmospheric correction procedure such as [8]. Then, a NIR water-leaving reflectance model, developed from in situ measurements, is used to calculate $L_{w}(\mathrm{NIR})$. The problem encountered with these algorithms is that the empirical bio-optical models limit their applicability to waters that are similar to those over which these empirical models were developed.

\section{Coupled ocean-atmosphere inversion}

As the ocean and the atmosphere cannot be decoupled in turbid waters $\left(L_{w}(\mathrm{NIR}) \neq 0\right)$, an appropriate solution for developing atmospheric correction scheme would be to couple the two systems and to inverse them together. In practice, this can be done using either artificial neural networks (NN) [41] or optimization techniques [20, 31, 36, 41, 50-54]. 
The more common type of NN is the Multi-Layer Perceptron (MLP) [55]. Thanks to this association of elementary tasks, an MLP is able to solve complex inverse problems. The specificity of an MLP depends on the topology of the neurons (number of layers, numbers of neurons on each layer) and on the connection weights $\mathrm{w}_{i j}$ from a neuron $\mathrm{j}$ of a layer to the neuron $i$ of the next layer. The $\mathrm{w}_{i j}$ weight values are computed through a training phase, using a training dataset. Once the training phase is finished, the MLP will only do algebraic operations, which leads to faster computations, which is very convenient for satellite applications. When using a neural network for the atmospheric correction phase, the top-of-atmosphere radiance is usually directly inverted for estimating the water-leaving radiance in the visible as well as the aerosol optical properties. Another option is to use optimization techniques. The principle of those algorithms is based on the iterative minimization of a dedicated cost function by adjusting relevant atmospheric (aerosol optical thickness, and Ångström coefficient) and oceanic (Chlorophyll concentration, IOPs) parameters which are the control parameters [20, 56]. There are some difficulties that one encounters when using this type of techniques: the parameters initialization [57], definition/use of a direct model, calculation of the adjoint code and the method for the parameters adjustment [56].

2. Are these algorithms accurate enough?

As shown previously, there are several methods to estimate $L_{w}$ from $L_{\text {ton }}$ in complex coastal waters. Few round-robin comparisons have been made to evaluate different atmospheric correction algorithms from in situ data [58, 59]. These studies showed that the different algorithms highly over-estimated $L_{w}$ in the blue and red and were quite accurate for the intermediate wavelengths providing similar estimates of $L_{w}$ (Figure 5). But the retrieval accuracy in the blue is still too low, with negative $L_{w}$ values in some cases, which prevent to use these bands for bio-optical applications.
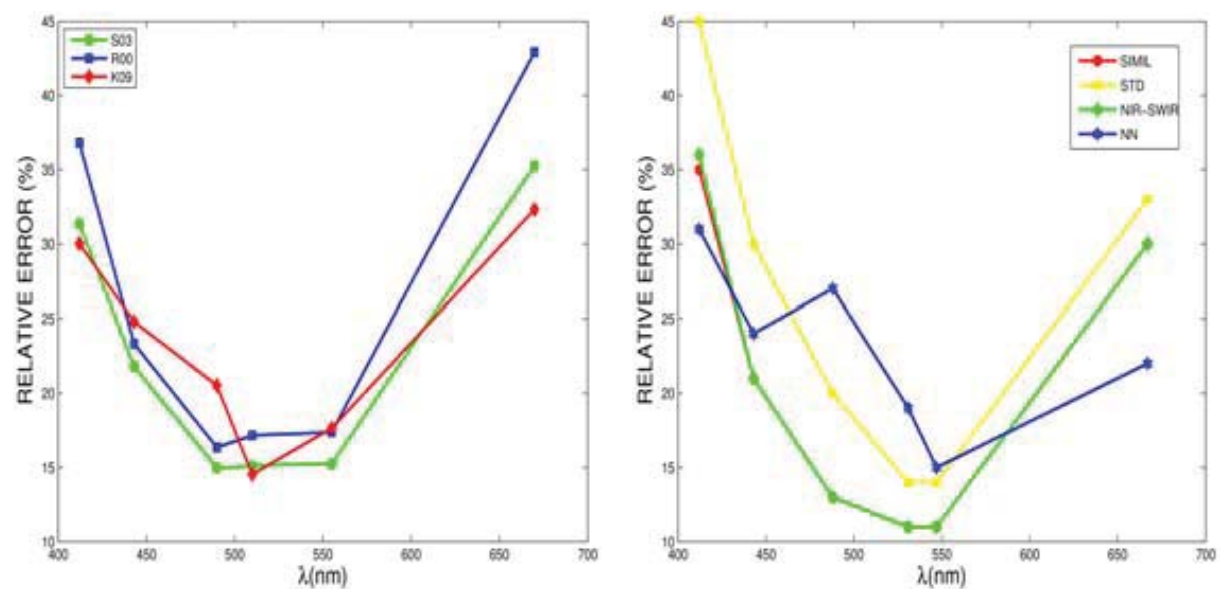

Figure 5. Evaluation of three SeaWiFS (left) and four MODIS-AQUA (right) atmospheric correction algorithms from insitu data in complex coastal waters (Figures from [58] and [59], respectively). 


\section{Other issues}

Besides the presence of water leaving radiance signal in the near infrared, other issues can be encountered during the atmospheric correction processing. The three major problems are the bottom albedo for shallow waters, the adjacency effects and the presence of absorbing aerosols.

The bottom effect corresponds to the light reflected off the bottom of a water body, providing the water is sufficiently shallow and clear. The influence of the seafloor on the colour of water depends on the depth of the water body, the clarity of the water masses, the type of optical substances present in the water, as well as on the type of substrate composing the seafloor. The bottom may be rocky or sandy, and may be covered, partially or fully, by a variety of benthic organisms (e.g., algae, mollusks). All of these factors will influence the manner in which bottom effects will act on the colour of the water, as seen by a remote sensor [27]. Figure 6 shows the particulate backscattering coefficient estimated at $490 \mathrm{~nm}$ using [60]. The area in light pink and white correspond to negative $\mathrm{R}_{r s}$ (and then $\mathrm{b}_{b p}$ ) values induced by this bottom effect. If this effect is not corrected before or during the atmospheric correction, the estimation of the $\mathrm{R}_{r s}\left(\mathrm{~b}_{b p}\right)$ will be biased and will lead often to obtain negative values. This is particularly true when studying clear shallow waters such as lagoons or the Coral Reefs Bareer in the east coast of Australia [61-63].

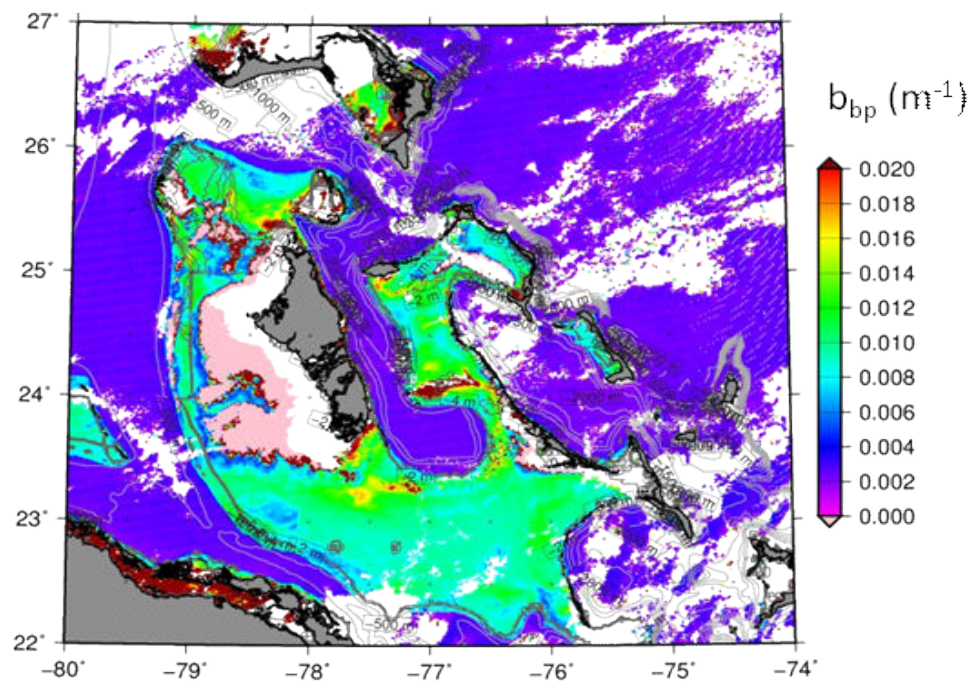

Figure 6. MODIS map showing the distribution of the backscattering coefficient of particulate matter $\left(b_{b p}, m^{-1}\right)$ estimated over shallow waters of the Bahamas using [60].

The so called "adjacency effect" refers to the process by which a photon, reflected from a surface adjacent to a targeted pixel, is scattered by the atmosphere between the sensor and the target, blurring the sharp boundary between the land and the coastal water [64-66]. In coastal areas, a fraction of the light reflected by the land can reach the sensor. Modeling the reduction of 
image contrast when the atmospheric turbidity increases requires large amounts of computing time. The adjacency effects impart a significant bias to the model for retrieval of aerosol values because of the high contrast between land and ocean in the near infrared spectral region. First, the aerosol optical thickness is overestimated by classic algorithm because of the increase of the atmospheric signal. Then the wavelength dependence is modified, leading to a wrong extrapolation of the aerosol optical thickness in the blue-green region. The variation of the aerosol optical thickness between the near infrared and the red on a transect from the coast can be a good indicator of contamination by adjacency effects of the aerosol product over land and an indicator of this effect on satellite imagery [66].

The third major problem is the presence of absorbing aerosols from urban and desert origin in coastal regions. The aerosol models used in the classic atmospheric correction are all nonor weakly absorbing $[8,9,67]$. Absorbing aerosols have a lower aerosol radiance at the shorter wavelengths than any of the models used in the current atmospheric correction process. The presence of absorbing aerosols would, thus, have a similar effect to the aforementioned incorrect model selection, though likely to a more significant degree in the blue portion of the spectrum. The presence of such strongly-absorbing aerosol can only be inferred in the visible, where multiple scattering is high. In such situations, one can no longer derive water properties by a two-step process - atmospheric correction followed by a bio-optical algorithm to estimate water properties. To solve this issue, only few methods have been currently proposed [20, 32, $51,53,68,69]$. A promising way to deal with the presence of absorbing aerosols would be to use spectral optimization method which allows the atmospheric and oceanic properties to be retrieved simultaneously.

\subsection{Bio-optical algorithms}

Satellite remote sensing of ocean colour is a very powerful tool for the management of resources and activities of continental shelf waters. Besides estimates of $C h l$, which represents the historical parameter investigated from optical remote sensing technique, more recent developments have allowed the retrieval of a variety of bio-optical (e.g. phytoplankton and detrital matter absorption or particulate backscattering coefficients) and biogeochemical (e.g. $P O C$, phytoplankton size distribution and community composition) parameters with now a satisfying accuracy at global scale [70]. The latter developments have been supported by the improvement of optical sensors, from the first (CZCS launched in 1978) to the most recent ones (e.g. SeaWiFS, MODIS or MERIS), both regarding the radiometric data quality and spatial resolution.

An accurate assessment in the coastal marine domain of the various optical and biogeochemical parameters previously cited and now available for oceanic waters still represents an important challenge since it would provide relevant and innovative insights on the dynamics and functioning of these complex and highly diverse ecosystems. The development of innovative bio-optical algorithms is for instance cruelly needed for precisely identifying the occurrence of specific phytoplankton species. As a matter of fact, a precise monitoring of harmful algal bloom (HAB) events which strongly impact the functioning of the concerned coastal ecosystems and which dynamics are currently relatively poorly constrained, represents a crucial field 
of investigation. Various algorithms have, in that sense been, proposed in the recent years for computing indices specifically dedicated to the identification of red tides events [71-73]. Among the various important challenges to overcome in coastal waters, one particularly crucial concerns the estimation of dissolved and particulate organic carbon stocks and dynamics which would strongly condition our ability to quantify the impact of coastal ecosystems domain on the global carbon cycle. The assessment of POC and DOC concentrations in coastal waters however still represents an open field of investigation even though some empirical regional algorithms have been already proposed for estimating DOC content from CDOM absorption coefficient retrieval in some coastal regions [74-76].

The assessment of the latter bio-optical and biogeochemical parameters from space depends on the relevance of the bio-optical algorithm required to infer marine water IOPs or biogeochemical products from satellite $L_{w}(\lambda)$ measurements. This key step for interpreting the satellite signal in these marine regions is complicated by various specific issues. Indeed, coastal waters are highly dynamic systems at both temporal and spatial scales being subjected to a variety of physical (tides, current, fronts, turbulence...) and environmental forcings (interactions with terrestrial ecosystems, phytoplankton blooms, re-suspension...). This high hydro-biological variability of these waters logically induces a strong optical complexity (Figure 7) making more difficult the interpretation of the 'color' in these environments. Specifically, unlike in case 1 waters, substances significantly active from an optical point of view (i.e. phytoplankton, nonalgal particles and colored dissolved material) usually vary independently in time and space and have specific optical properties which may vary over wide ranges [77-79]. These specificities of coastal waters create different issues. First, a strong dispersion around the average general laws generally used in open ocean waters for linking the radiometric measurements to bio-optical (absorption and backscattering coefficients) or biogeochemical parameters (e.g. chlorophyll a). The latter feature prevents the use of Case 1-like general relationships and emphasizes the crucial need to develop specific inversion schemes allowing to take into account for the peculiar optical characteristics of the coastal marine domain [27, 80, 81]. Second, standard algorithms used for estimating ocean colour such as Chla concentration in oceanic waters are based on reflectance ratios in the blue and green spectral domain [27]. In coastal waters, the significant contribution of dissolved and particulate non-algal material to the optical budget at these latter wavelengths complicates our ability to detect phytoplankton pigment optical signal and often induces a strong failure in the accuracy of these classical formulations (Figure 8).

Accurate assessment of the different in water bio-optical components from ocean colour measurements in coastal areas are therefore largely controlled by: (i) our ability to understand and to account for the origin of the variability in the radiometric signal and (ii) the realism of the parameterizations used between the inherent optical properties (IOPs) and the biogeochemical component (BC). Numerous challenges still remain $[17,27]$ in that sense, however some progresses have been recently performed by developing inversion approaches specifically dedicated to face the various issues encountered in coastal waters (see sections 3.3 and 3.4). 

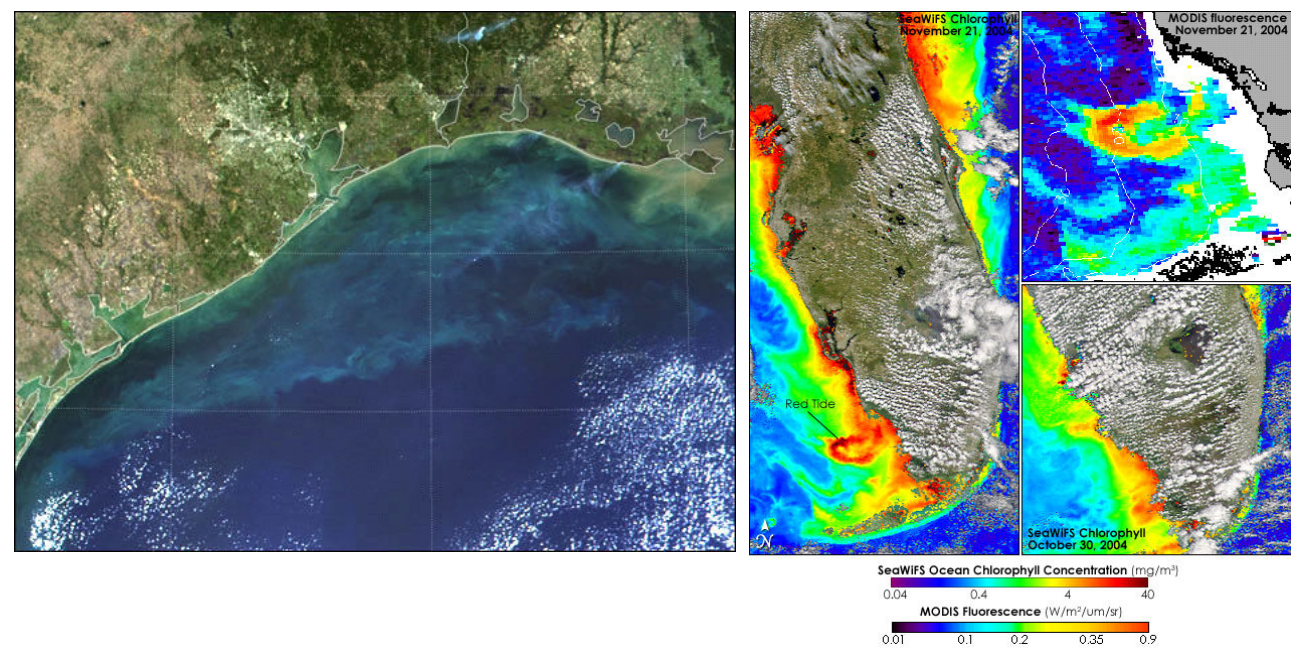

Figure 7. Left: MODIS true color image of a red tide event occurring in the coastal water of Texas. Right: SeaWiFS and MODIS maps showing quantitative estimates of phytoplankton Chla associated with red tides events in the coastal zone of Florida (http://earthobservatory.nasa.gov).

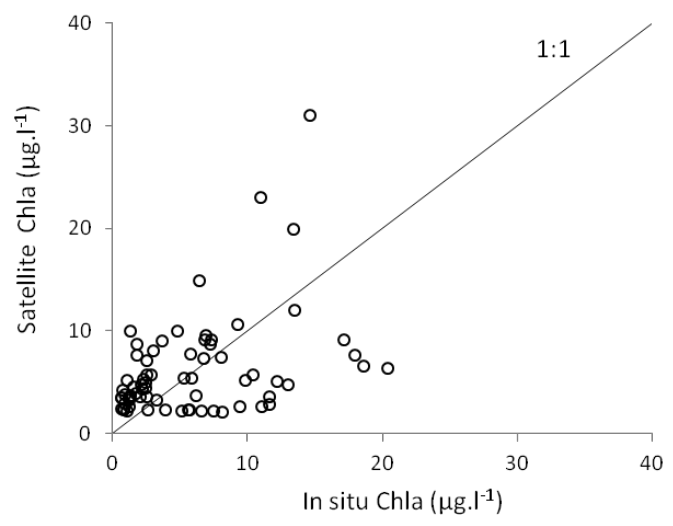

Figure 8. SeaWiFs (OC4V4 algorithm) matchups of Chla performed in coastal areas of the English Channel and southern north Sea (Loisel unpublished data).

\subsection{Validation}

Validation of ocean color products (i.e. $L_{w}(\lambda)$, IOPs, and biogeochemical parameters) should theoretically be performed from in situ measurements acquired simultaneously to the satellite overpass over the same location. However, these ideal conditions are rarely encountered and specific protocols should be applied [82, 83]. For instance, it is in practice recommended to use a 2-hour time window applied to the satellite overpass time at the measurement site to select 
satellite imagery. Second, the match-up procedure extracts a 3-by-3 pixel satellite image box with the middle pixel closest to the measurement site. The mean value of the desired parameter over the box is calculated for each image. Lastly, an atmospheric spatial uniformity criterion is applied, based on a prescribed coefficient of spatial variation, defined as the ratio of the standard deviation to the mean pixel value within the selected image box. This match-up exercise is made more complicated for coastal waters where typical high frequency physical and biological processes cause high temporal variability and strong spatial heterogeneity (Figure 9). In situ measurements are generally performed from oceanographic vessel or instrumented fixed buoy from which the spatial heterogeneity of the satellite pixel can not be necessarily taken into account. Typical pixel size of ocean color missions is about $1 \times 1 \mathrm{~km}^{2}$ at nadir, even if higher spatial resolution data (about 250x250 m) are now accessible for some specific wavelengths (i.e. MODIS), or over the whole spectrum but only on request, that is not routinely (i.e. MERIS-FR). Thanks to the very recent development of autonomous underwater vehicles such as gliders, equipped with optical and radiometric sensors, the spatial heterogeneity of a given pixel could now be sampled in situ. However, much more researches are needed to reach the level of accuracy needed for ocean color validation, from measurements collected using these new platforms.
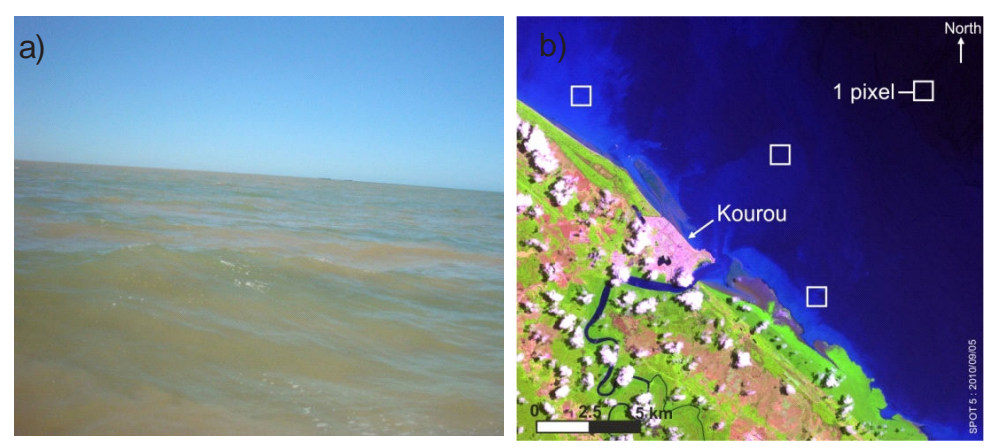

Figure 9. a) Picture of turbid patches found in the French Guyana coastal waters taken during a scientific mission in October 2009 [84]. (b) High resolution SPOT image showing the wide optical dynamics of the coastal waters of French Guiana. The white square Figures a 1x1 km pixel typically considered for ocean color remote sensing application.

\section{New and futures developments of ocean color remote sensing of coastal areas}

\subsection{Cloud masking}

Prior to any application of atmospheric correction and bio-optical algorithms a cloud masking algorithm should be applied over the satellite observed area. For that purpose, different algorithms which differ by their inherent assumptions and the wavelengths used have been developed [85-89]. The standard algorithms to process the image acquired by SeaWiFS [85] 
and MODIS [89] use a constant threshold value at $865 \mathrm{~nm}$ (SeaWiFS) and $869 \mathrm{~nm}$ (MODIS) over which the pixel is considered as cloud. Wang and Shi [86] present a more sophisticated algorithm based on the fact that water is almost totally black in the shortwave infrared (SWIR) wavelengths. The latter authors have also proposed an alternative algorithm for ocean color sensors which do not allow for measurements in the SWIR bands (such as SeaWiFS and MERIS). Basically, this algorithm is based on the assumption that the spectral variability in the NIR is lower for clouds than for water. Based on the observation that water is generally spatially more homogeneous than clouds, the cloud mask for the POLarization and Directionality of the Earth's Reflectances (POLDER) sensor uses a threshold on the spatial variability in $865 \mathrm{~nm}$ [87]. To be able to automatically process and exploit the long time series of SeaWiFS ocean color images over coastal areas, a recent algorithm has been developed for the SeaWiFS sensor [88]. This algorithm is mainly based on the spectral differences of the Rayleigh free TOA signal between cloud and turbid waters. Performance of different algorithms for the very turbid waters of the Amazon delta is provided in Figure 10.
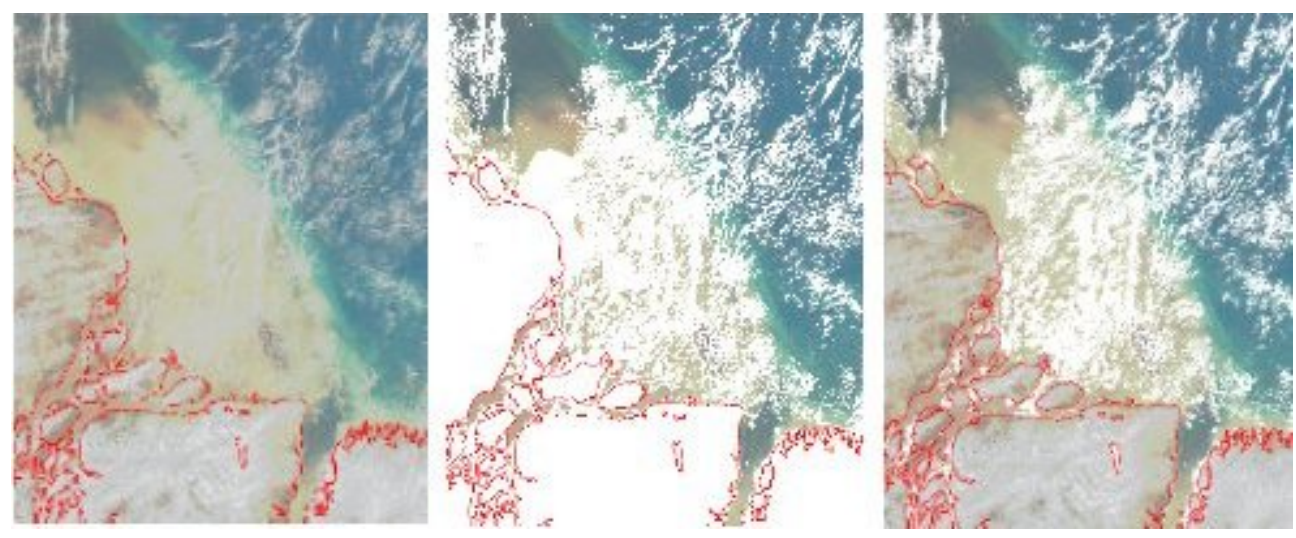

Figure 10. A color composite SeaWiFS image recorded over the Amazon delta area with no cloud mask (left), and after the application of the standard SeaWiFS NIR threshold (middle), and Nordkvist et al. [88] algorithm (right). The gain of clear water pixels is clearly seen when the latter algorithm is used instead of the standard SeaWiFS algorithm.

\subsection{Atmospheric correction}

As shown in Figure 5, the accuracy of the existing atmospheric correction algorithms is still not enough satisfying, especially when considering the blue and red spectral bands. It is therefore still necessary to develop innovative schemes to decrease the errors at these bands. As mentioned previously, one of the most promising algorithm development suggests the use of the shortwave infra-red bands (SWIR) for estimating the atmospheric path radiance [44, 47]. However, because of the low signal-to-noise ratio of the MODIS-AQUA SWIR bands, which induces uncertainties in the extrapolation of the aerosol models from the SWIR to the NIR and visible, and also due to the fact that none of the future ocean color sensors (OLCI, GOCI-II, OCAPI, S-GLI) will possess the SWIR bands, it is necessary to find other ways to 
improve the atmospheric correction procedure. Another promising option would be to consider the shorter wavelengths, i.e. in the ultraviolet bands [90]. For highly productive waters with high amount of colored dissolved organic matter, the water-leaving reflectance at $412 \mathrm{~nm}$ can be used to constrain the aerosol model retrieval considering that $L_{w}(412)$ is relatively low being negligible when compared to $L_{w}$ in the visible and NIR bands. Considering the latter feature, UV bands could be used to determine the aerosol model. The major disadvantage of using the UV for the atmospheric correction is the assumption of a negligible $L_{w}$ for these bands which are important for the retrieval of CDOM. This assumption needs to be further validated by increasing the amount of dedicated in situ data in the future.

Another way for improving atmospheric correction schemes in coastal waters would be to further develop the use of the formulations which consider a definition of the NIR bio-optical algorithms, by adding constrains on the relationships between $L_{w}$ at several wavelengths. Several relationships already exist. For instance, Wang et al. [46] proposed a new atmospheric correction algorithms for the GOCI sensor using a relationship between $L_{w}(765)$ and $L_{w}(865)$. However, this algorithm needs in a preliminary step to calculate the diffuse attenuation coefficient, $K_{d}(490)$ for estimating $L_{w}(765)$ from the MODIS-AQUA sensor using the SWIR atmospheric correction algorithm. This step might add errors and complexity for developing such algorithms. This emphasizes also the need for developing more direct approaches. One solution would be to mix a new formulation of the NIR similarity spectrum approach [40,91] such as defined in $[59,92]$ with the algorithm developed by [31] which has been demonstrated to be robust in low but also very turbid waters. Figure 11 presents evaluation of the similarity spectrum [40, 91] and formulation of Doron et al. [92] against in-situ data for moderately and highly turbid waters. We can see that the constant $R_{r s}(\mathrm{NIR})$ ratios is not valid for those waters, notably for highly turbid waters. These ratios could be integrated inside a current atmospheric correction algorithm for constraining the inversion. Another way is to find linear or polynomial relationships between two $R_{r s}$ (Figure 12).

\subsection{Bio-optical algorithms: The classification approach vs. regional approaches}

Different approaches have been considered in the recent years for developing inversion algorithms in order to face the issue represented by the strong optical complexity and heterogeneity of coastal waters (see section 3.3). Two contrasted approaches based on a geographical or optical partition of the coastal waters will be considered here, both aiming to constrain the dispersion around bio-optical $\mathrm{R}_{r s}(\lambda)$-IOPs-BC relationships and presenting their own advantages and requirements.

The first approach, which is the more usual one, consists in focusing on the range of optical variability specific to a defined coastal area by developing local or regional, usually empirical inversion algorithms [93-95]. This way of dealing with the optical complexity of coastal waters, although relatively convenient to implement (as soon as a reasonable amount of in situ measurements are available for a defined region) might present different limitations in its application. Indeed, while such regional algorithms may reduce the variability in the IOPs-BC relationships, they are highly dependent on the dataset used for their development. In other terms, the accuracy of regional relationships mostly depends on their ability to account for the 
(a)

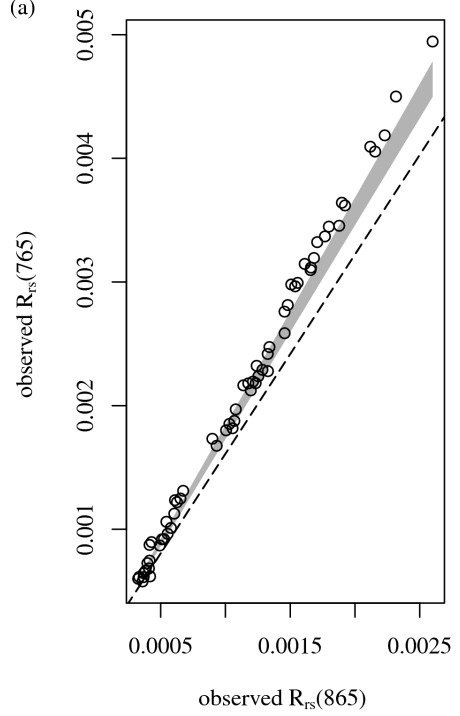

(b)

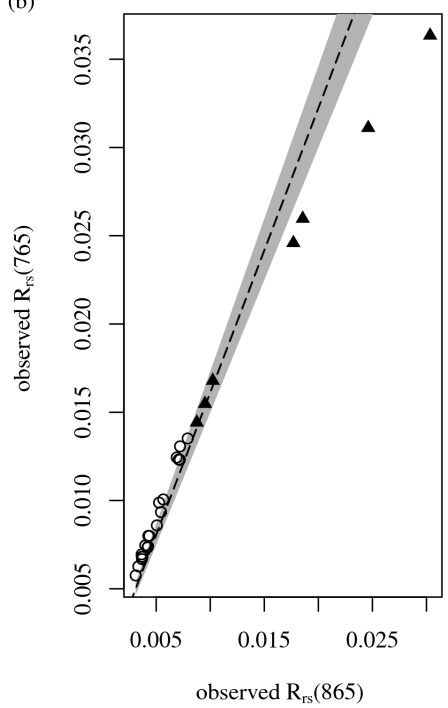

Figure 11. Reflectance ratio at 765 and $865 \mathrm{~nm}$ according to [91] (dashed line) and [92] (grey polygon) for (a) moderately and (a) highly turbid waters [59]. Circles and triangles are for data collected in the Eastern English Channel/North Sea and the French Guiana, respectively.

natural variability of the water masses optical properties occurring in a defined region. However, a relationship defined for a given area is likely to vary over time (i.e. at the daily scales, seasonal or inter-annual) since it depends strongly on the combined action of various environmental forcing (phytoplankton blooms, in suspension, leaching of the sides, riverine inputs and advection of the offshore waters....). Furthermore, considering the high dynamics of coastal ecosystems it might be presumably challenging to capture, even for a defined region, the many high-frequency processes affecting bio-optical relationships. Finally, in the scope of applications of remote sensing techniques in coastal waters over large spatial scales (i.e. global), the use of a regional approach (by definition non-exportable geographically) would consist in performing a collection of algorithms developed on a mosaic of coastal areas. This seems both difficult to implement in practice and would inevitably lead to ignore some coastal areas currently not covered by ad hoc in situ measurements.

Another way to deal with the optical heterogeneity of the coastal domain is to specifically consider the optical diversity of these waters within the algorithm development procedure. In practice, this alternative approach to regional methods is based on optical classifications, which aims at grouping waters with similar optical features and develops optically adapted algorithms for each water class. Such a definition of optical water types implicitly assumes that different coastal regions can present similar optical characteristics of the marine components 

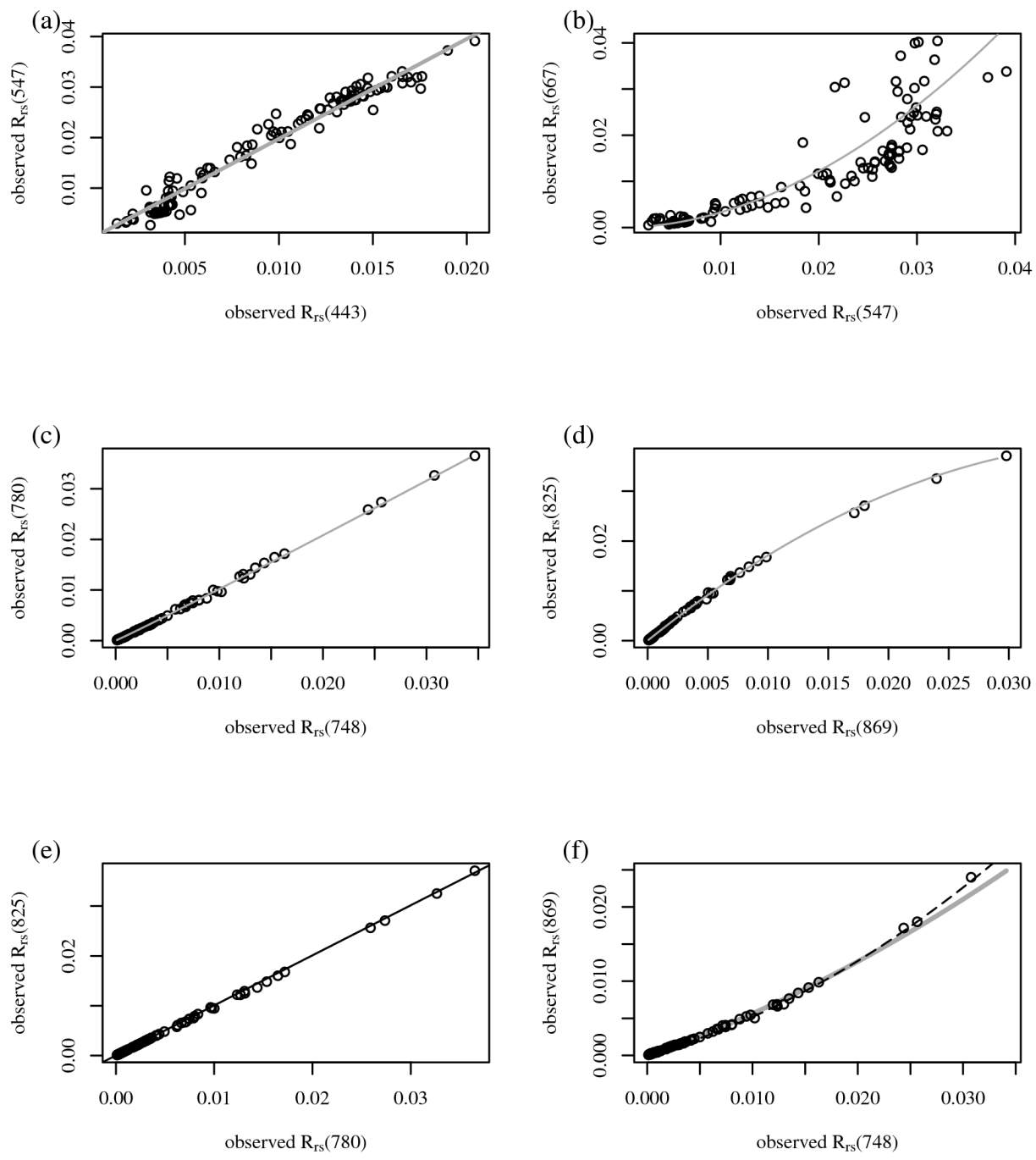

Figure 12. a) Linear relation between $\operatorname{Rrs}(\lambda)$ at 443 and $547 \mathrm{~nm}, \mathrm{~b})$ Polynomial relation between $\operatorname{Rrs}(\lambda)$ at 547 and 667 $\mathrm{nm}, \mathrm{c})$ constant ratio between $\operatorname{Rrs}$ at 748 and $780 \mathrm{~nm}, \mathrm{~d})$ Polynomial relation between $\operatorname{Rrs}(\lambda)$ at 820 and $869 \mathrm{~nm}$, e) constant ratio between the modeled $\operatorname{Rrs}(\lambda)$ at 780 and $825 \mathrm{~nm}, \mathrm{f})$ polynomial relation between $\operatorname{Rrs}(\lambda)$ at 748 and 869 $\mathrm{nm}$ [59]. For this latter figure, the dotted line represents the polynomial regression line over the in-situ dataset. The grey thick line represents the polynomial relationship defined by [59].

which translate into similar reflectances, at least during some moments of the year. Classification-based approaches are therefore intrinsically independent of the location and the time, 
and thus present a stronger universal character being presumably more suitable for large scale applications than classical regional approaches. Previous studies have treated the partition of the marine waters into optical classes. They were based on sets of bio-optical parameters diversely including the following: the diffuse attenuation coefficient, the Secchi depth or inherent optical properties and biogeochemical parameters [12, 96-98]. Other studies, in particularly, at global scale, were dedicated to optical water type definition based on the information provided by the remote sensing reflectance spectra $[99,100]$. These studies have emphasized the potential of using ocean typology based on ocean color radiometry for characterizing the uncertainties related to ocean color products [101] and improving the performance of the inversion procedure [102]. Furthermore, the advantage of the optical classification approach for providing relevant insights into ocean water masses optical dynamics and therefore studying its biogeochemical quality has also been illustrated for the open ocean waters [103]. Similar applications of optical classification dedicated to the coastal ocean are currently limited. Few studies have specifically focused on a characterization of the optical diversity of coastal water masses from in situ measurements [83, 105].

Satellite applications of coastal ocean optical typology for monitoring coastal water quality [106] or improving ocean color product inversion [107, 108] are also still relatively scarce. A recent study [109] performed from an in situ data set gathered in contrasted coastal waters (i.e. eastern English Channel, southern North Sea and French Guiana) has emphasized the applicability and the advantages of this approach (Figure 13). Specifically the main results of this study have emphasized that (i) the ubiquitous character of $R_{r s}$ spectra optical shape at global scale (ii) the need of a reasonable amount of optical classes for describing coastal waters optical diversity (iii) the interest of the optical classification for dynamically monitoring the coastal waters masses quality and (iv) the potential for this approach for improving estimates of satellite products (with preliminary results on the SPM retrieval). The potential of the classification-based approach should be however explored more in detail through the establishment of large data set coupling optical and biogeochemical measurements gathered in a large variety of coastal waters.

\subsection{The need of other "tools"}

a. Towards the use of other spectral domains

The past and present ocean color sensors are generally characterized by a common set of spectral channels. The blue $(412,443,490 \mathrm{~nm})$ and green $(510,550 / 560 \mathrm{~nm})$ wavelengths are used for bio-optical algorithms purposes whereas the red (670) and near infrared $(765,865 \mathrm{~nm})$ wavebands are used for atmospheric corrections. To these standard ocean color channels, some sensors also have the ability to measure the chlorophyll-a fluorescence peak using a band centered at about $676 \mathrm{~nm}$ in combination with two surrounding bands (around 665 and 746 $\mathrm{nm}$ ) used for the baseline [110]. To overcome the challenges of ocean color remote sensing of coastal areas, the use of visible wavelengths other than the standard ones should also be examined. For instance, the maximum reflectance signal observed in coastal areas is, in many cases, observed around $590 \mathrm{~nm}$, which is far from the 550/560 standard bands which can not adequately capture this maximum (Figure 14). Because of the generally low absorption 

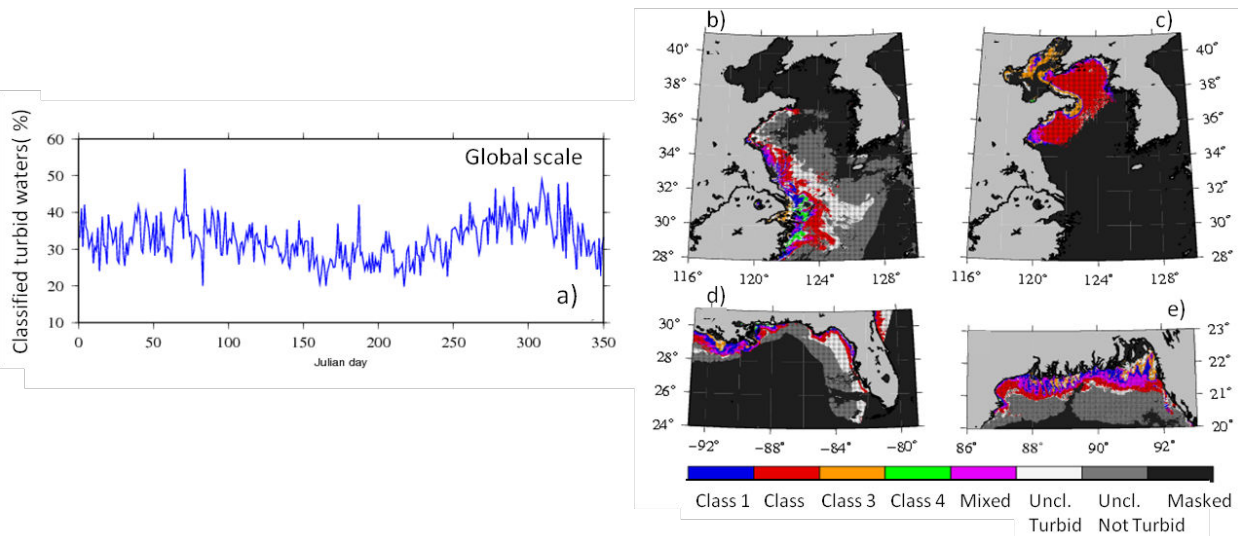

Figure 13. a) Annual evolution of the percentage of SeaWiFS turbid pixels [85] labeled as belonging to one of the four optical water types defined from our in situ data set at global scale. Illustrations of the optical water types distribution $(b, c)$ in the China sea coastal waters, $d$ ) in the northern Gulf of Mexico and e) in the coastal waters influenced by the Gange-Brahmaputra rivers output. White pixels correspond to unclassified turbid waters, light and dark grey show non-turbid and masked regions, respectively (taken from [110]).

coefficient at this wavelength, it could also be used to improve the determination of the spectral slope of the particulate backscattering coefficient [18].

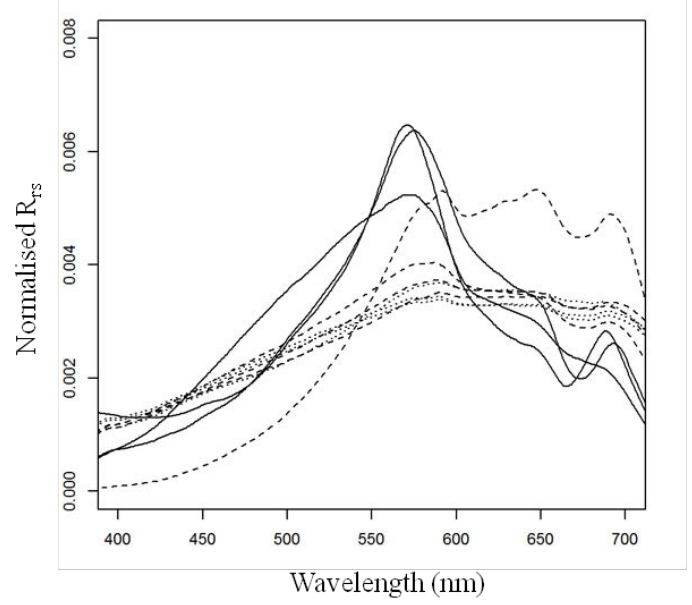

Figure 14. Example of normalized remote sensing spectra, $R_{\mathrm{rs}}$ collected in various coastal environments (English Channel, North Sea, and French Guyana). The description of this data set can be found in [105]. The normalization has been performed by dividing raw $\mathrm{R}_{\mathrm{rs}}$ spectrum by its integrated value in order to emphasize changes in the shape of the reflectance found in coastal waters. 
The recent use of the ultraviolet (UV) bands in the frame of the development of ocean color algorithms over coastal waters has shown some promising results. For instance, the exponential increase of detritus and colored dissolved organic matter absorption coefficient from the long to the short wavelengths makes the UV domain an ideal candidate for atmospheric correction purposes in turbid waters [90]. This new method, which based on a low and relatively stable water reflectance signal in the UV, does therefore not require any assumption on the water inherent optical properties. Based on the same observations, the $412 \mathrm{~nm}$ channel has previously been used with success in an atmospheric correction scheme applied over the Chesapeake region [39].

The ultraviolet spectral domain is also essential for assessing information about the colored dissolved organic matter distribution as already illustrated by recent works [111, 112]. The advantage of using $\mathrm{nLw}(325) / \mathrm{nLw}(565)$ have been for instance emphasized by the latter authors for specifically assessing $\mathrm{a}_{C D O M}$ coefficient. Specifically, the interest of using of the UV reflectance signal stands in its ability for minimizing the potential issues represented by the overlapping of CDOM and phytoplankton absorption spectra occurring for the classically used blue and green bands. Indeed, in the UV domain CDOM is expected to dominate the absorption budget of the non-water compounds while the contribution of phytoplankton photoprotective compounds such as microsporine-like amino acids [113], although still uncertain, is expected to be relatively restricted in this spectral region. In addition to a gain in CDOM retrieval accuracy, the use of successive UV bands for deriving CDOM absorption from the marine reflectance signal would provide the opportunity to derive information on CDOM spectral slope which might provide innovative information on the nature of CDOM [114, 112].

Besides, reflectances in the near infrared domain have also been demonstrated to be of particular interest for estimating the SPM concentration from satellite imagery [e.g. AVHRR: [115]; MODIS, MERIS SeaWiFS: [116]]. In this spectral domain, direct relationships between NIR-reflectance and SPM values appear indeed to be robust due to the very low influence of $\mathrm{CDOM}$ absorption at these wavelengths. The latter reason has also led to the development of a variety of Chla inversion algorithms based on red and NIR wavelengths [117-122] allowing to avoid issues related to the use of classical blue/green reflectance ratios and taking in some cases advantages of the Chla fluorescence properties in the latter spectral domains.

\section{Directional polarized measurements}

While the UV and NIR spectral domains are excellent candidates to overcome the challenges of ocean color remote sensing of coastal areas, the use of directional polarized radiometric measurements in the visible should also be examined. The inverse methods used to estimate the optical (IOPs) and biogeochemical parameters (i.e. Chl, POC, etc) information from space are based on different assumptions and mathematical developments. However, they all use the total remote sensing reflectance, $\mathrm{R}_{r s}(\lambda)$, as input parameters (or a similar radiometric quantity). While theoretical and field measurements have highlighted that the polarization of the underwater light field is sensitive to the nature of the suspended marine particles (for example phytoplankton vs. mineral), none of these models exploits the linear polarization of the upwelling light field from the ocean surface. This is due to the fact that the marine polarized 
signal only represents a small fraction of the signal measured from space (about $10 \%$ of the total marine signal) which makes this measurement very challenging. Recent studies have however showed that space measurement of the polarized light field in different directions could provide useful information for both advanced atmospheric correction and bio-optical algorithms [123, 124]. For instance, the signal measured from the POLarization and Directionality of the Earth's Reflectances sensor (POLDER-2) over turbid areas has been found in excellent agreement with theory with regards to its variability with the bulk particulate matter [123]. However, the exploitation of such measurements in the frame of algorithms development for the futures ocean color missions requires an excellent radiometric resolution.

3. Hyperspectral measurements

Hyperspectral sensors cover the visible and near infrared spectra with a much more complete spectral resolution, compared to multispectral ocean color sensors which have about 8 (i.e. MODIS) to 15 (i.e. MERIS) spectral bands in this spectral domain. For instance, the Hyperspectral Imager for the Coastal Ocean (HICO), operating on the international Space Station (ISS), specifically samples the coastal ocean every $5.7 \mathrm{~nm}$ [125]. Such high spectral resolution, associated with a high signal-to-noise ratio, allow the spectral features of the observed scene to be resolved. The interest of hyperspectral measurements compared to multispectral measurements for spatial ocean color applications is still under debate. However, more and more studies emphasize the importance of hyperspectral remote sensing data for phytoplankton detection, optically significant water constituents assessment, as well as bottom characterization [126-130]. Most of these studies are based on the derivative spectroscopy technique which enhances subtle spectral features present over hyperspectral data. While the second derivative of the radiometric signal allows specific spectral features to be detected, it is also much less sensitive to the presence of additional material such as colored dissolved organic matter which generally biases the standard algorithms based on a restricted number of wavelengths [128]. Futures ocean color sensors such as the HYPERSPECTRAL IMAGER (HSI) on board EnMAP will offer the opportunity to go further in the exploitation of hyperspectral data for ocean color applications.

4. Advanced statistical methods

Due to the complexity of the coastal waters, the estimation of the water contents are more and more difficult to obtain with a high accuracy as shown in the previous sections. Therefore, there is a need in developing innovative inversion methods. Advanced statistic methods that can be very promising for the monitoring of the ocean color are the machine learning. These methods, developed initially for computational/artificial intelligence, are now more and more used in environmental sciences. As they have shown their utility in climate, meteorology, atmospheric sciences, satellite data processing, analysis and modeling of environmental data, weather prediction, they can be very helpful for studying the ocean color. Several studies already exist for the application of artificial neural networks for the atmospheric correction processing [50-52, 20, 57, 41], the estimation of the chlorophyll-a concentration [54, 131-136], the inherent optical properties retrieval [33, 137-138] or the diffuse attenuation coefficient [139]. But there exists other types of machine learning that the community could use such as the 
support vector machine [140, 141], the unsupervised competitive learning [142], regression trees [143], non-linear principal component [144], canonical correlation analysis [145]. These methods can be used for regression analysis for the direct estimation of water constituents, for classification (water types, phytoplankton functional groups) and for analysis of time series. For instance, Figure 15 shows a comparison of different algorithms for the estimation of the spectral diffuse attenuation coefficient $K_{d}(490)$ [139]. The use of a NN (bottom right Figure) allows to decrease the error for the estimation of moderate and high values of $K_{d}(490)\left(K_{d}(490)>\right.$ $\left.0.5 \mathrm{~m}^{-1}\right)$.
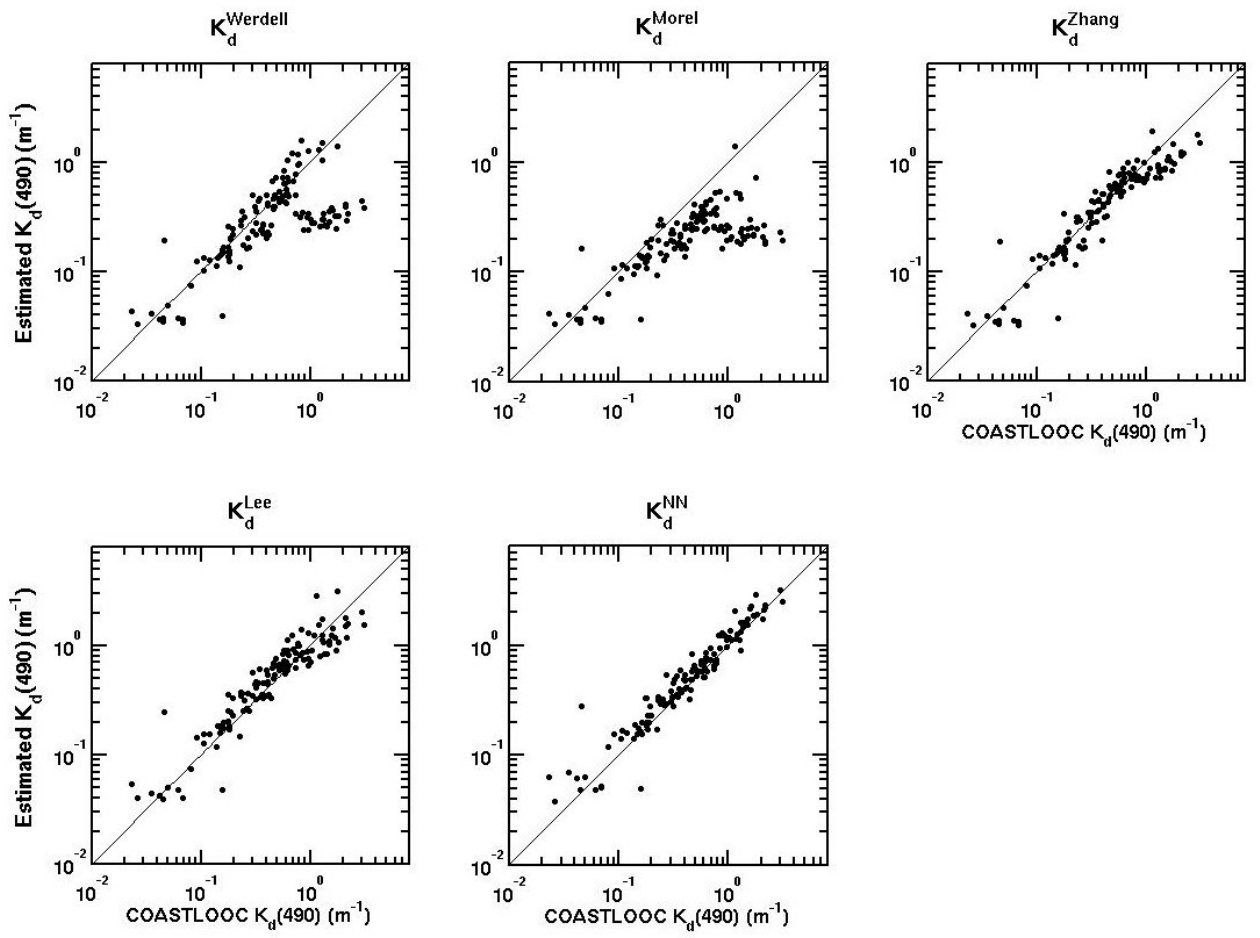

Figure 15. Scatterplots of desired $K_{d}(490)$ versus estimated $K_{d}(490)$ values retrieved with five algorithms using a coastal data set gathering measurements collected in coastal waters all around Europe [77]. The continuous line represents the $1: 1$ line. Figure from [139].

5. High spatial and temporal resolutions satellite data

A high spatial resolution is required for ocean color remote sensing of coastal waters to catch the high spatial variability generally occurring in these areas, as well as for validation purposes. The recent development of geostationary ocean colour sensors will increase the precision of the remote sensing measurements and will provide relevant insights for the study of marine biogeochemical cycles [146, 147]. Geostationary satellites continuously view the same region 
of the earth's surface. It thus allows obtaining high quality and frequent observations of a defined area. Such an instrument is therefore particularly useful in order to follow the response of marine ecosystems to short-term variations in the environmental conditions. In particularly, it is of interest for monitoring the effects of rivers plumes and tidal front and mixing on the biotic and abiotic material present in coastal areas or assessing the effects of exceptional events (storms, red tides, dissemination of sediments or pollutants). It will also provide relevant information for biogeochemical modelling purposes as well as for research activities related to the biogeochemical cycles at daily scales. South Korea's instrument on board the COMS-1 satellite (GOCI, Geostationary Ocean Color Imager), which has been recently launched (2010), is the first ocean-colour sensor in a geostationary orbit. The target area of GOCI covers a large region $(2500 \times 2500 \mathrm{~km})$ around the Korean peninsula. Its resolution is $500 \mathrm{~m}$ while it acquires data at a 1 hour frequency. The other ocean color geostationary missions which are currently planned (OCAPI-CNES, GeoCape-NASA) will increase the spatial coverage and the number of information delivered by such sensors.

\section{Conclusions}

The use of ocean color remote sensing in coastal waters offers a capability to routinely monitor the surface water constituents over large areas. Thanks to our better understanding of the remote sensing signal, as well as to the improvement sensor technology, new innovative products, compared to the historical chlorophyll concentration, are now available, at least at regional scales. One may cite for instance the colored dissolved organic matter, and concentration and nature of suspended particulate matter. Such information coupled with other data coming from other satellite observations (sea surface temperature, wind speed and direction, sea surface elevations) and physical and ecological modeling provide essential inputs to understand the complex bio-physical coupling occurring in coastal waters. For instance, the coupling between bottom sediment resuspension and observed surface suspended particulate matter has been stressed using satellite and physical modeling [148]. In the same way, based on the synergic use of satellite products deriving from ocean color observations, thermal measurements, and sea surface height, tight coupling bio-physical processes can now be examined [149]. While numerous ocean color products are now available in coastal areas, their assessment is not as accurate as for open ocean waters. Note that there is still no consensus of the community for a common algorithm to assess the chlorophyll concentration in coastal areas. One of the major issues is the retrieval of the marine radiometric signal from the top of atmosphere (i.e. the atmospheric corrections). Numerous new methods, listed in the present chapter, are now developed to address this particular point. A second issue is related to the bio-optical algorithms development. In the frame of algorithms development, new paths, compared to the ones used for open ocean waters, are still in the experimental phase. Among them, the simultaneous retrieval of atmospheric and oceanic components, the algorithms based on the classification approaches, as well as the exploitation of geostationary ocean color sensors should open new ways in a recent future. 


\section{Acknowledgements}

This work has been supported by the ANR programme in the frame of the GlobCoast ANR-11BLANC-BS56-018_01 project (www.foresea.fr/globcoast/)

\section{Author details}

Hubert Loisel ${ }^{1,2,3}$, Vincent Vantrepotte ${ }^{2}$, Cédric Jamet ${ }^{2}$ and Dinh Ngoc Dat ${ }^{3}$

1 Laboratoire d'études en Géophysique et océanographie spatiales (LEGOS) CNRS: UMR5566 - IRD - CNES - Observatoire Midi-Pyrénées - INSU - Université Paul Sabatier Toulouse, France

2 Laboratoire d'Océanologie et des Géosciences (LOG), INSU-CNRS, UMR 8187, Université Lille Nord de France, ULCO, Wimereux, France

3 Space Technology Institute (STI), Vietnam Academy of Science \& Technology (VAST). Hanoi, Vietnam

\section{References}

[1] Taylor AH, Allen JI, Clark PA. Extraction of a weak climatic signal by an ecosystem. Nature 2002; 416 629-632.

[2] Hays CG. Effect of Nutrient Availability, Grazer Assemblage and Seagrass Source Population on the Interaction Between Thalassia Testudinum (Turtle Grass) and its Algal Epiphytes. Journal of Experimental Marine Biology and Ecology 2005; 314 53-68.

[3] Paerl, HW. Assessing and Managing Nutrient-Enhanced Eutrophication in Estuarine and Coastal Waters: Interactive Effects of Human and Climatic Perturbations. Ecological Engineering 2006; 26 40-54.

[4] Wollast R. Evaluation and Comparison of the Global Carbon Cycle in the Coastal Zone and in the Open Ocean. In: K. H. Brink and A. R. Robinson (eds.). The Global Coastal Ocean. John Wiley \& Sons; 1998. p213-252.

[5] Naqvi, S.W.A.; Unnikrishnan, A.S. 2009. Hydrography and biogeochemistry of the coastal ocean In: Le Quere C, Saltzman E. (eds.) Surface ocean - Lower atmosphere processes. AGU; 2009. p233-250.

[6] auer, JE, Druffel ERM. Ocean Margins as a Significant Source of Organic Matter to the Deep Open Ocean. Nature 1998; 392 482-485. 
[7] Hedges JL. Global Biogeochemical Cycles: Progress and Problems. Marine Chemistry 1992; 39 67-93.

[8] Gordon HR, Wang M. Retrieval of Water-Leaving Radiance and Aerosol Optical Thickness Over the Oceans with SeaWiFS: A Preliminary Algorithm. Applied Optics 1994; 33 443-452.

[9] Antoine D, Morel A. A Multiple Scattering Algorithm for Atmospheric Correction of Remotely-Sensed Ocean Colour (MERIS Instrument): Principle and Implementation for Atmospheres Carrying Various Aerosols Including Absorbing Ones. International Journal of Remote Sensing 1999; 20(9) 1875-1916.

[10] Morel A., editor. Minimum Requirements for an Operational Ocean-Colour Sensor for the Open Ocean. International Ocean Color Coordinating Group; 1998.

[11] Gordon HR, McCluney WR. Estimation of the Depth of Sunlight Penetration in the Sea for Remote Sensing. Applied Optics 1975, 14 413-416.

[12] Smith RC, Baker KS. Optical Classification of Natural Waters; Limnology \& Oceanography 1978; 23(2) 260-267.

[13] McClain CR. A Decade of Satellite Ocean Color Observations. Annual Review of Marine Science 2009; 1 19-42.

[14] Stramski D, Reynolds RA, Babin M, Kaczmarek S, Lewis MR, Röttgers R, Sciandra A, Stramska M, Twardowski MS, Claustre H. Relationships Between the Surface Concentration of Particulate Organic Carbon and Optical Properties in the Eastern South Pacific and Eastern Atlantic Oceans. Biogeosciences 2008; 4 1041-1058.

[15] Loisel H, Nicolas JM, Deschamps PY, Frouin R. Seasonal and Inter-Annual Variability of the Particulate Matter in the Global Ocean. Geophysical Research Letters 2002; 29(24) DOI:10.1029/2002GLO15948.

[16] Duforet-Gaurier L, Loisel L, Dessailly D, Nordkvist K, Alvain, S. Estimates of Particulate Organic Carbon over the Euphotic Depth from In Situ Measurements. Application to Satellite Data over the Global Ocean. Deep-Sea Research I 2010; 57 351-367

[17] Lee Z-P., editor. Remote Sensing of Inherent Optical Properties: Fundamentals, Tests of Algorithms and Applications. International Ocean Color Coordinating Group; 2006.

[18] Loisel, Nicolas J-M, Sciandra A, Stramski D, Poteau A. Spectral Dependency of Optical Backscattering by Marine Particles from Satellite Remote Sensing of the Global Ocean. Journal of Geophysical Research 2006; 111(C9) C0902410.1029/2005JC003367.

[19] Bricaud A, Ciotti AM, Gentili B. Spatial-Temporal Variations in Phytoplankton Size and Colored Detrital Matter Absorption at Global and Regional Scales, as Derived from Twelve Years of SeaWiFS Data (1998-2009). Global Biogeochemical Cycles 2012; 26 doi:10.1029/2010GB003952. 
[20] Jamet C, Thiria S, Moulin, Crepon, M. Use of a Neuro-Variational Inversion for retrieving Oceanic and Atmospheric Constituents from Ocean Color Imagery: a Feasibility Study. Journal of Atmospheric and Oceanic Technology 2005; 22(4) 460-475.

[21] Sathyendranath S, Watts L, Devred E, Platt T, Caverhill C, Maass H. Discrimination of Diatoms from Other Phytoplankton using Ocean-Colour Data. Marine Ecology Progress Series 2005; 272 59-68.

[22] Alvain S, Moulin C, Dandonneau Y, Breon F-M. Remote Sensing of Phytoplankton Groups in Case 1 Waters from Global SeaWiFS imagery. Deep Sea Research Part I 2005; 52(11) 1989-2004.

[23] Ciotti A, Bricaud A. Retrievals of a Size Parameter for Phytoplankton and Spectral Light Absorption by Colored Detrital Matter from Water-Leaving Radiances at SeaWiFS Channels in a Continental Shelf Region off Brazil, Limnology 1 Oceanography Methods 2006; 4 237-253.

[24] Kostadinov TS, Siegel DA, Maritorena S. Retrieval of the Particle Size Distribution from Satellite Ocean Color Observations. Journal of Geophysical Research 2009; 114 doi:10.1029/2009JC005303.

[25] International Ocean Color Coordinating Group. http:www.ioccg.org (accessed 14 October 2012).

[26] Alvain S, Moulin C, Dandonneau H, Loisel H. Seasonal Distribution and Succession of Dominant Phytoplankton Groups in the Global Ocean: A satellite view. Global Biogeochemical Cycles 2008; 22(3) DOI: 10.1029/2007GB003154.

[27] Sathendranath S., editor. Remote sensing of Ocean Colour in coastal and Other Optically-Complex, Waters. International Ocean Color Coordinating Group; 2003.

[28] Gordon HR. Atmospheric Correction of Ocean Color Imagery in the Earth Observing System Era. Journal of Geophysical Research 1997;102(D14) 17081-17106.

[29] Robinson, IS. Satellite Observations of Ocean Colour, Philosophical Transactions of the Royal Society of London Series A- Mathematical Physical and Engineering Sciences 1983;309(1508) 338-347.

[30] Siegel DA, Wang MH, Maritorena S, Robinson W. Atmospheric Correction of Satellite Ocean Color Imagery: the Black Pixel Assumption. Applied Optics 2000;39(21) 3582-3591.

[31] Bailey SW, Franz BA, Werdell PJ. Estimation of Near-Infrared Water-Leaving Reflectance for Satellite Ocean Color Data Processing. Optics Express 2010;18 7521-7527.

[32] Brajard, J, Jamet C, Moulin C, Thiria S. Use of a Neuro-Variational Inversion for Retrieving Oceanic and Atmospheric Constituents from Satellite Ocean Colour Sensor: Application to Absorbing Aerosols. Neural Networks 2006;19 178-185. 
[33] Doerffer R, Schiller H. The MERIS Case 2 Water Algorithm. International Journal of Remote Sensing 2007;28 517-535.

[34] Dogliotti A-I, Ruddick K, Nechad B, Lasta C, Mercado A, Hozbor C, Guerrero R, Riviello López G, Abelando M. Calibration and validation of an algorithm for remote sensing of turbidity over La Plata River estuary, Argentina. In: Reuter R (eds) EARSeL eProceedings, 5th EARSeL Workshop on Remote Sensing of the Coastal Zone, $1^{\text {st }}$ - $3^{\text {rd }}$ June 2011, Prague, Czech Republic. Oldenbrug: BIS-Verlag; 2011.

[35] Hu C, Carder KL, Muller-Karger FE. Atmospheric Correction of SeaWiFS Imagery over Turbid Coastal Waters. Remote Sensing of Environment 2000; 74 195-206.

[36] Kuchinke CP, Gordon HR, Franz BA. Spectral Optimization for Constituent Retrieval in Case II Waters I: Implementation and Performance. Remote Sensing of Environment 2009;13 571-587.

[37] Land PE, Haigh, JD. Atmospheric Correction over Case 2 Waters with an Iterative Fitting Algorithm. Applied Optics 1996;35 5443-5451.

[38] Lavender SJ, Pinkerton MH, Moore GF, Aiken J, Blondeau-Patissier D. Modification to the Atmospheric Correction of SeaWiFS Ocean Colour Images over Turbid Waters. Continental Shelf Research 2005; 25 539-555.

[39] Oo, M, Vargas M, Gilerson A, Gross B, Moshary F, Ahmed S. Improving Atmospheric Correction for Highly Productive Coastal Waters using the Short Wave Infrared Retrieval Algorithm with Water-Leaving Reflectance Constraints at $412 \mathrm{~nm}$. Applied Optics 2008;47(21) 3846-3859.

[40] Ruddick K, Ovidio F, Rijkeboer M. Atmospheric Correction of SeaWiFS Imagery for Turbid Coastal and Inland Waters. Applied Optics 2000;39(6) 897-912.

[41] Schroeder T, Behnert I, Schaale M, Fischer J, Doerffer R. Atmospheric Correction Algorithm for MERIS above Case-2 Waters. International Journal of Remote Sensing 2007;28 1469-1486.

[42] Shanmugam, P, Ahn, YH.. New Atmospheric Correction Technique to Retrieve the Ocean Colour from SeaWiFS Imagery in Complex Coastal Waters. Journal of Optics A: Pure and Applied Optics 2007;9 511-530.

[43] Stumpf RP, Arnone RA, Gould RW, Ransibrahmanakul V. A Partly Coupled OceanAtmosphere Model for Retrieval of Water-Leaving Radiance from SeaWiFS in Coastal Waters. NASA technical memorandum 2003; 206892(22).

[44] Wang MH, Shi S. Estimation of Ocean Contribution at the MODIS Near-Infrared Wavelengths along the East Coast of the US: Two Case Studies. Geophysical Research Letters 2005;32(13) DOI: 10.1029/2005GL022917 
[45] Wang, M, Son S, and Shi W. Evaluation of MODIS SWIR and NIR-SWIR Atmospheric Correction Algorithms using SeaBASS Data, Remote Sensing of Environment 2009; 113 635-644.

[46] Wang MH, Shi W, Jiang LD. Atmospheric Correction using Near-Infrared Bands for Satellite Ocean Color Data Processing in the Turbid Western Pacific region. Optics Express 2012; 20(2) 741-753.

[47] Wang MH, Shi W. The NIR-SWIR Combined Atmospheric Correction Approach for MODIS Ocean Color Data Processing. Optics Express 2007;15 15722-15733.

[48] Shi W, Wang MH. An Assessment of the Black Ocean Pixel Assumption for MODIS SWIR Band. Remote Sensing of Environment 2009;113 1587-1597.

[49] Werdell PJ, Franz BA, Bailey SW. Evaluation of Shortwave Infrared Atmospheric Correction for Ocean Color Remote Sensing of Chesapeake Bay. Remote Sensing of Environement 2010; 114 2238-2247.

[50] Brajard J, Jamet C, Moulin C, Thiria S. Validation of a Neuro-Variational Inversion of Ocean Colour Images. Advances in Space Research 2006;38 2169-2175.

[51] Brajard, J, Moulin C, Thiria S. Atmospheric Correction of SeaWiFS Ocean Color Imagery in the Presence of Absorbing Aerosols off the Indian Coast using a Neuro-Variational Method. Geophysical Research Letters 2008;35 doi:10.1029/2008GL035179.

[52] Brajard J, Santer R, Crépon M, Thiria S. Atmospheric Correction of MERIS Data for Case-2 Waters using a Neuro-Variational Inversion. Remote Sensing of Environment 2012;126 51-61.

[53] Chomko, RM, Gordon HR. Atmospheric Correction of Ocean Color Imagery: Use of the Junge Power-Law Aerosol Size Distribution with Variable Refractive Index to Handle Aerosol Absorption. Applied Optics 1998;37 5560-5572.

[54] Schiller H, Doerffer R. Neural Network for the Evaluation of the Inverse Model: Operational Derivation of Case 2 Water Properties from MERIS Data. International Journal of Remote Sensing 1997;20 1735-1746.

[55] Bishop CM., editor. Neural Networks for Pattern Recognition. Oxford University Press; 1995.

[56] Jamet, C., and H. Loisel. 2009. Data Assimilation in Surface Ocean/Lower Atmosphere Processes. Geophysical Monograph 187. Editors C. Le Quere and E. Saltzman. AGU (pp 329).

[57] Jamet, C, Moulin, Thiria S. Monitoring Aerosol Optical Properties over the Mediterranean from SeaWiFS Images using a Neural Network Inversion. Geophysical Research Letters 2004; 31 doi:10/1029/2004GL019951. 
[58] Jamet C, Loisel H, Kuchinke CP, Ruddick K, Zibordi G, Feng H. Comparison of Three SeaWiFS Atmospheric Correction Algorithms for Turbid Waters using AERONET-OC Measurements. Remote Sensing of Environment 2011;115(8) 1955-1965.

[59] Goyens C, Jamet C, Ruddick K. Validation of Marine Models for Visible and Near Infra-Red Wavelengths as used for Turbid Water Atmospheric Correction. Optics Express 2012; submitted.

[60] Loisel H, Stramski D. Estimation of the Inherent Optical Properties of Natural Waters from Irradiance Attenuation Coefficient and reflectance in the Presence of Raman Scattering. Applied Optics 2000; 39(18): 3001-3011.

[61] Goodman JA, Lee Z-P, Ustin SL. Influence of Atmospheric and Sea-Surface Corrections on Retrieval of Bottom Depth and Reflectance using a Semi-Analytical Model: a Case Study in Kaneohe Bay, Hawaii. Applied Optics 2008;47 F1-F11.

[62] Mobley CD. Zhang H, Voss K. Effects of Optically Shallow Bottoms on Upwelling Radiances: Bidirectional Reflectance Distribution Function Effects. Limnology and Oceanography 2003;48 337-345.

[63] Ohde T, Siegel H. Correction of Bottom Influence in Ocean Colour Satellite Images of Shallow Water Areas of the Baltic Sea. International Journal of Remote Sensing 2001;22 297-313.

[64] Tanré D, Herman M, Deschamps P-Y. Influence of the Background Contribution upon Space Measurements of Ground Reflectance. Applied Optics 1981;20 3676-3684.

[65] Tanré D, Herman M, Deschamps P-Y, de Leffe A. Atmospheric Modeling for Space Measurements of Ground Reflectances, including Bidirectional Properties. Applied Optics 1979;18 3587-3594.

[66] Santer R, Schmechtig C. Adjacency Effects on Water Surfaces: Primary Scattering Approximation and Sensitivity Study. Applied Optics 2000; 39(3) 361-375.

[67] Ahmad Z, Franz BA, McClain CR, Kwiatkowska EJ, Werdell J, Shettle EP, Holben BN. New Aerosol Models for the Retrieval of Aerosol Optical Thickness and Normalized Water-Leaving Radiances from the SeaWiFS and MODIS Sensors over Coastal Regions and Open Oceans. Applied Optics 2010; 49(29) 5545-5560.

[68] Moulin C, Gordon HR, Banzon VF, Evans RH. Assessment of Saharan Dust Absorption in the Visible from SeaWiFS Imagery. Journal of Geophysical Research 2001;106 18239-18249.

[69] Banzon VF, Gordon HR, Kuchinke CP, Antoine D, Voss KJ, Evans RH. Validation of a SeaWiFS Dust-Correction Methodology in the Mediterranean Sea: Identification of an Algorithm-Switching Criterion. Remote Sensing of Environment 2009; 113 2689-2700. 
[70] Platt T, Hoepffner N, Stuart V, Brown C., editors. Why Ocean Colour? The Societal Benefits of Ocean- Colour Technology. International Ocean Color Coordinating Group; 2008.

[71] Hu C, Muller-Karger FE, Taylor C, Carder KL, Kelble C, Johns E, Heil CA. Red Tide Detection and Tracing using MODIS Fluorescence Data: A Regional Example in SW Florida Coastal Waters. Remote Sensing of Environment 2005;97 311 - 321.

[72] Ahn Y-H, Shanmugam P. Detecting the Red Tide Algal Blooms from Satellite Ocean Color Observations in Optically Complex Northeast-Asia Coastal Waters. Remote Sensing of Environment 2006; 103 419-437.

[73] Ishizaka J, Kitaura Y, Touke Y, Sasaki H, Tanaka A, Murakami H, Suzuki T, Matsuoka K, Nakata H. Satellite Detection of Red Tide in Ariake Sound, 1998-2001. Journal of Oceanography 2006;62 37-45.

[74] Mannino A, Russ ME, Hooker SB. Algorithm Development and Validation for Satellite-Derived Distributions of DOC and CDOM in the U.S. Middle Atlantic Bight. Journal of Geophysical Research 2008;113 doi:10.1029/2007JC004493.

[75] Del Castillo CE, Miller RL. On the Use of Ocean Color Remote Sensing to Measure the Transport of Dissolved Organic Carbon by the Mississippi River plume. Remote Sensing of Environment 2008;112 836-844.

[76] Matsuoka A, Bricaud A, Benner R, Para J, Sempéré R, Prieur L, Bélanger S, Babin M. Tracking the Transport of Colored Dissolved Organic Matter in the Southern Beaufort Sea: Relationship with Hydrographic Characteristics. Biogeosciences 2012;9 925940.

[77] Babin M, Stramski D, Ferrari GM, Claustre H, Bricaud A, Obolensky G, Hoepffner N. Variations in the Light Absorption Coefficients of Phytoplankton, Nonalgal Particles, and Dissolved Organic Matter in Coastal Waters around Europe. Journal of Geophysical Research 2003;108(C7) doi:10.1029/2001JC000882.

[78] Loisel H, Mériaux X, Berthon J-F, Poteau A. Investigation of the Optical Backscattering to Scattering Ratio of Marine Particles in Relation to their Biogeochemical Composition in the Eastern English Channel and southern North Sea. Limnology and Oceanography 2007;52(2) 739-752.

[79] Vantrepotte V, Brunet C, Mériaux X, Lécuyer E, Vellucci V, Santer R. Bio-Optical Properties of Coastal Waters in the Eastern English Channel. Estuarine Coastal and Shelf Science 2007; 72(1-2) 201-212.

[80] Darecki M, Stramski D. An Evaluation of MODIS and SeaWiFS Bio-Optical Algorithms in the Baltic Sea. Remote Sensing of Environment 2004;89 326-350.

[81] Loisel H, Lubac B, Dessailly D, Duforêt-Gaurier L, Vantrepotte V. Effect of Inherent Optical Properties Variability on the Chlorophyll Retrieval from Ocean Color Remote Sensing: an In Situ Approach. Optics Express 2010; 18(20) 2010. 
[82] Bailey S, Wang M. Satellite aerosol optical thickness match-up procedures. NASA technical memorandum 2001; 2001-209982 70-72.

[83] Feng H, Campbell JW, Dowell MD, Moore TS. Modeling Spectral Reflectance of Optically Complex Waters using Bio-Optical Measurements from Tokyo Bay. Remote Sensing of Environment 2005;99(3) 232-243.

[84] Vantrepotte V, Loisel H, Mériaux X, Neukermans G, Dessailly D, Jamet C, Gensac E, Gardel A. Seasonal and Inter-Annual (2002-2010) Variability of the Suspended Particulate Matter as Retrieved from Satellite Ocean Color Sensor over the French Guiana Coastal Waters. Journal of Coastal Research 2011;64 1750-1754.

[85] Robinson WD, Franz BA, Patt FS, Bailey SW, Werdell PJ. Masks and Flags Updates. NASA Technical Memorandum 2003;22 34-40.

[86] Wang M., Shi W. Cloud Masking for Ocean Color Data Processing in the Coastal Regions. IEEE Transaction on Geoscience \& Remote Sensing 2006;44 3196-3205.

[87] Nicolas J-M, Deschamps P-Y, Loisel H, Moulin C. Algorithm Theoretical Basis Document, POLDER-2 / Ocean Color / Atmospheric corrections. http://smsc.cnes.fr/ POLDER/A_produits_scie.htm (accessed 17 October 2012).

[88] Nordkvist K, Loisel H, Duforêt-Gaurier L. Cloud Masking of SeaWiFS Images over Coastal Waters using Spectral Variability. Optics Express 2009; 17(15) 1224612258.

[89] Feldman GC, McClain CR. Ocean Color Web, SeaWiFS Reprocessing 5.2. http:// oceancolor.gsfc.nasa.gov.

[90] He X, Bai Y, Pan D, Tang J, Wang D. Atmospheric Correction of Satellite Ocean Color Imagery using the Ultraviolet Wavelength for Highly Turbid Waters. Optics Express 2012;20(18) 20754-20770.

[91] Ruddick K, De Cauwer V, Park Y, Moore G. Seaborne Measurements of Near Infrared Water-Leaving Reflectance: The Similarity Spectrum for Turbid Waters. Limnology and Oceanography 2006; 51(2) 1167-1179.

[92] Doron M, Bélanger S, Doxaran D, Babin M. Spectral Variations in the Near-Infrared Ocean Reflectance. Remote Sensing of Environment 2011; 115(7) 1617-1631.

[93] D'Sa EJ, Miller RL, Del Castillo C.. Bio-optical Properties and Ocean Color Algorithms for Coastal Waters Influenced by the Mississippi River during a Cold Front. Applied Optics 2006;45 7410-7428.

[94] Garcia VMT, Signorini SR, Carcia CAE, McClain CR. Empirical and Semi-Analytical Chlorophyll Algorithms in the South-Western Atlantic Coastal Region (25-40 $\mathrm{S}$ and $\left.60-45^{\circ} \mathrm{W}\right)$. International. Journal of Remote Sensing 2006; 27(8) 1539-1562.

[95] Kowalczuk P, Darecki M, Zabłocka M, Górecka I. Validation of Empirical and SemiAnalytical Remote Sensing Algorithms for Estimating Absorption by Colored Dis- 
solved Organic Matter in the Baltic Sea from SeaWiFS and MODIS Imagery. Oceanologia 2010;, 55(2) 171-196.

[96] Baker KS, Smith RC. Bio-Optical Classification and Model of Natural Waters. 2. Limnology and Oceanography 1982; 27(3) 500-509.

[97] Prieur L., Sathyendranath S. An Optical Classification of Coastal and Oceanic Waters based on the Specific Spectral Absorption Curves of Phytoplankton Pigments, Dissolved Organic Matter, and other Particulate Materials. Limnology and Oceanography 1981;26 671-689.

[98] Reinart A, Herlevic A, Arstb H, Sipelgas L. Preliminary Optical Classification of Lakes and Coastal Waters in Estonia and South Finland. Journal of Sea Research 2003;49 357-366.

[99] Moore TS, Campbell JW, Feng H. A fuzzy logic classification scheme for selecting and blending satellite ocean color algorithms. IEEE Transactions on Geoscience and Remote Sensing 2001; 39(8) 1764-1776.

[100] Moore TS, Campbell JW, Dowell MD. A Class-Based Approach to Characterizing and Mapping the Uncertainty of the MODIS Ocean Chlorophyll Product. Remote Sensing of Environment 2009;113 2424-2430.

[101] D'Alimonte D, Mélin F, Zibordi G, Berthon, J-F. Use of the Novelty Detection Technique to Identify the Range of Applicability of the Empirical Ocean Color Algorithms. IEEE Transactions on Geoscience and Remote Sensing 2003;41 2833-2843.

[102] Szeto M, Moore TS, Campbell JW, Werdell PJ. Are the World's Oceans Optically Different, Journal of Geophysical Research-Oceans 2011;116. doi: 10.1029/2011JC007230.

[103] Forget M-H, Stuart V, Platt T., editors. Remote Sensing in Fisheries and Aquaculture. International Ocean Color Coorditaning Group; 2009.

[104] Lubac B, Loisel H.. Variability and Classification of Remote Sensing Reflectance Spectra in the Eastern English Channel and Southern North Sea. Remote Sensing of Environment 2007;110, 45-58.

[105] Tilstone GH, Angel-Benavides IM, Pradhan Y, Shutler JD, Groom S, Sathyendranath S. An Assessment of Chlorophyll-a Algorithms Available for SeaWiFS in Coastal and Open Areas of the Bay of Bengal and Arabian Sea. Remote Sensing of Environment 2011;115 2277-2291

[106] Hommersom A, Wernand MR, Peters S, Eleveld MA, van der Woerd HJ, de Boer J.. Spectra of a Shallow Sea - Unmixing for Class Identification and Monitoring of Coastal Waters. Ocean Dynamics 2011;61 463-480.

[107] Le C, LI Y, Zha Y, Sun D, Huang C, Zhang H. Remote Estimation of Chlorophyll a in Optically Complex Waters based on Optical Classification. Remote Sensing of Environment 2010;115(2) 725-737. 
[108] Mélin F, Vantrepotte V, Clerici M, D'Alimonte D, Zibordi G, Berthon J.F. Multi-Sensor Satellite Time Series of Optical Properties and Chlorophyll a Concentration in the Adriatic Sea. Progress in Oceanography 2011;31 229-244.

[109] Vantrepotte V, Loisel H, Dessailly D, Mériaux X. Optical Classification of Contrasted Coastal Waters. Remote Sensing of Environment 2012;123 306-323.

[110] Hoge FE, Lyon PE, Swift RN, Yungel JK, Abbott MR, Letelier RM, Esaias WE. Validation of Terra-MODIS Phytoplankton Chlorophyll Fluorescence Line Height. I. Initial Airborne Lidar Results. Applied Optics 2003. 42(15) 2767-2771.

[111] Hooker SB, CR McClain, Mannino A. NASA Strategic Planning Document: A Comprehensive Plan for the Long-Term Calibration and Validation of Oceanic Biogeochemical Satellite Data. NASA Special Publication 2007; SP-2007-214152 1- 31

[112] Tedetti M, Charrière B, Bricaud A, Para J, Raimbault P, Sempéré R. Distribution of Normalized Water-Leaving Radiances at UV and Visible Wavebands in Relation with Chlorophyll a and Colored Detrital Matter Content in the South East Pacific. Journal of Geophysical Research 2010;115 doi:10.1029/2009JC005289.

[113] Vernet M, Whitehead K. Release of Ultraviolet-Absorbing Compounds by the RedTide dinoflagellate Lingulodinium Polyedra. Marine Biology 1996;127 35-44.

[114] Fichot, C. G., and R. Benner. A Novel Method to Estimate DOC Concentrations from CDOM Absorption Coefficients in Coastal Waters. Geophysical Research Letters 2011;38 doi:10.1029/2010GL046152.

[115] Myint, S.W., and N. Walker. Quantification of Surface Suspended Sediments Along a River Dominated Coast with NOAA AVHRR and SeaWiFS Measurements: Louisiana, USA. International Journal of Remote Sensing 2002. 23(16): 3229-3249.

[116] Nechad, B., Ruddick K.G. and Park Y. Calibration and validation of a generic multisensor algorithm for mapping of total suspended matter in turbid waters. Remote Sensing of Environment 2010, 114, 854-866.

[117] Gower, J., King, S. Validation of chlorophyll fluorescence derived from MERIS on the west coast of Canada. International Journal of Remote Sensing 2007, 28, 625-635

[118] Gons, H. -J., Rijkeboer, M., Ruddick, K. -G.. A chlorophyll-retrieval model for satellite imagery (Medium Resolution Imaging Spectrometer) of inland and coastal waters. Journal of Plankton Research, 2002, 24, 947-951.

[119] Gitelson, A. -A., Dall'Olmo, G., Moses, W., Rundquist, D., Barrow, T., Fisher, T. -R. A simple semi-analytical model for remote estimation of chlorophyll-a in turbid productive waters: Validation. Remote Sensing of Environment 2008, 112, 3582-3593.

[120] Gilerson, A., Gitelson, A. -A., Zhou, J., Gurlin, D., Moses, W. -J., Ioannou, I. Algorithms for remote estimation of chlorophyll-a in coastal and inland waters using red and near infrared bands. Optics Express 2011, 18, 24109-24125. 
[121] Yang, W., Matsushita, B., Chen, J., Fukushima, T., Ma, R. An enhanced threeband index for estimating chlorophyll-a in turbid case-II waters: Case studies of Lake Kasumigaura, Japan, and Lake Dianchi, China. IEEE Geoscience and Remote Sensing Letters 2010, 7, 655-659.

[122] Gurlin, D., Gitelson, A. A., Moses, W. J. Remote estimation of chl-a concentration in turbid productive waters - Return to a simple two-band NIR-red model? Remote Sensing of Environment 2011; 115(12), 3479-3490.

[123] Loisel H, Duforet L, Dessailly D, Chami M, Dubuisson P. Investigation of the Variations in the Water Leaving Polarized Reflectance from the POLDER Satellite Data over two Biogeochemical Contrasted Oceanic Areas. Optics Express 2008; 16(17) 12905-12918.

[124] Harmel T, Chami M. Influence of Polarimetric Satellite Data Measured in the Visible Region on Aerosol Detection and on the Performance of Atmospheric Correction Procedure over Open Ocean Waters. Optics Express 2008; 19 (21), 20960-20983

[125] Lucke, R. L., M. Corson, N. R. McGlothlin, S. D. Butcher, D. L. Wood, D. R. Korwan, R. R. Li, W. A. Snyder, C. O. Davis, and D. T. Chen. Hyperspectral Imager for the Coastal Ocean: instrument description and first images. Applied Optics 2011; 50(10), 1501-1516.

[126] Lee, Z., K.L. Carder, C.D. Mobley, R.G. Steward, and J.S. Patch. Hyperspectral Remote Sensing for Shallow Waters. 2. Deriving Bottom Depths and Water Properties by Optimization. Applied Optics 1999; Vol. 38, Issue 18, pp. 3831-3843.

[127] Craig, S.E., S.E. Lohrenz, Z. Lee, K.L. Mahoney, G.J. Kirkpatrick, O.M. Schofield, and R.G. Steward. Use of hyperspectral remote sensing reflectance for detection and assessment of the harmful alga, Karenia brevis, Applied Optics. 2006; 45, 5414- 5425.

[128] Lubac, B., H. Loisel, N. Guiselin, R. Astoreca, L.F. Artigas, and X. Mériaux. Hyperspectral and multispectral ocean color inversions to detect Phaeocystis globosa blooms in coastal waters. Journal of Geophysical Research 2008; 113, C06026. doi: 10.1029/2007JC004451.

[129] Louchard, E.M., R.P. Reid, C.F. Stephens, C.O. Davis, R.A. Leathers, R. A., Downes, T. V., et al. Derivative analysis of absorption features in hyperspectral remote sensing data of carbonate sediments. Optics Express 2002; 10, 1573-1584.

[130] Torrecilla, E., D. Stramski, R. A. Reynolds, E. Millán-Núñez, and J. Piera. Cluster analysis of hyperspectral optical data for discriminating phytoplankton pigment assemblages in the open ocean. Remote Sensing of Environment 2011; 115, 2578-2593.

[131] Buckton, D., E. O'Mongain, and S. Danaher. The use of neural networks for the estimation of oceanic constituents based on the MERIS instrument. International Journal of Remote Sensing 1999; 20, 1841-1851. 
[132] D'Alimonte, D., and G. Zibord. Phytoplankton determination in an optically complex coastal region using a multilayer perceptron neural network. IEEE Trans. Geosci. Remote Sensing 2003; 41, 2861-2868.

[133] Gonzales Vilas, L., E. Spyrakos, and J. M. Torres-Palenzuela. Neural network estimation of chlorophyll a from MERIS full resolution data for the coastal waters of Galician rias (NW Spain), Remote Sensing of Environment 2011; 115, 524-535.

[134] Gross, L., S. Thiria, R. Frouin, and B. G. Mitchell. Artificial neural network for modeling the transfer function between marine reflectance and phytoplankton pigment concentration. Journal of Geophysical Research 2000; 105, 3483-3495.

[135] Tanaka, A., M. Kishino, R. Doerffer, H. Schiller, T. Oishi, and T. Kubota. Development of a neural network algorithm for retrieving concentrations of chlorophyll, suspended matter and yellow substance from radiance data of the ocean color and temperature scanner, J. Oceanography 2004; 60, 519-530.

[136] Zhang, T., F. Fell, Z. S. Liu, R. Preusker, J. Fischer, and M. X. He. Evaluating the performance of artificial neural network techniques for pigment retrieval from ocean color in case I waters. Journal of Geophysical Research 2003; 108(C9), 3286, doi: 10.1029/2002JC001638.

[137] Bricaud, A., C. Mejia, D. Biondeau-Patissier, H. Claustre, M. Crepon, and S. Thiria. Retrieval of pigment concentrations and size structure of algal populations from their absorption spectra using multilayered perceptrons. Applied Optics 2007; 46, $1251-1260$.

[138] Ioannou, I., A. Gilerson, B. Gross, F. Moshary, and S. Ahmed. Neural network approach to retrieve the inherent optical properties of the ocean from observations of MODIS. Applied Optics 2011; 50, 3168-3186.

[139] Jamet, C., H., Loisel and D., Dessailly. Retrieval of the spectral diffuse attenuation coefficient $\operatorname{Kd}(\lambda)$ in open and coastal ocean waters using a neural network inversion. Journal of Geophysical Research 2012; 117, doi:10.1029/2012JC008076.

[140] Vapnik, V.N. (1995). The Nature of Statistical Learning Theory, Springer-Verlag Eds, Berlin.

[141] Vapnik, V.N. (1998). Statistical Learning Theory, Wiley Edzs, New York.

[142] Kohonen T. Self-Organizing Maps, Third extended edition. Springer; 2001.

[143] Breiman L, Friedman JH, Olshen RA, Stone CJ. Classification and Regression Trees. Wadsworth; 1983.

[144] Hsieh WW. Nonlinear Principal Component Analysis by Neural Networks. Tellus Series A-Dynamic Meteorology and Oceanography 2001;53(5) 599-615.

[145] Hsieh WW. Nonlinear Canonical Correlation Analysis by Neural Network. Neural Networks 2000;13(10) 1095-1105. 
[146] Choi, J.-K., Y. J. Park, J. H. Ahn, H.-S. Lim, J. Eom, and J.-H. Ryu. GOCI, the world's first geostationary ocean color observation satellite, for the monitoring of temporal variability in coastal water turbidity. Journal of Geophysical Research 2012; 117, C09004, doi:10.1029/2012JC008046.

[147] Lei, M., Roman, A., Bricaud, A., Froidefond, J.M., Mathieu, S., and P. Gouton. Simulation of future geostationary ocean color images. IEEE Journal of Selected Topics in Applied Earth Observations and Remote Sensing 2012; 5, 1, 173-182.

[148] Ouillon S., P. Douillet, and S. Andréfouët. Coupling satellite data with in situ measurements and numerical modeling to study fine suspended sediment transport: a study for the lagoon of New Caledonia, Coral Reefs 2004; 23 (1), 109-122.

[149] Arnon, R.A., and A.R. Parsons. Real-time use of ocean color remote sensing for coastal monitoring. Remote Sensing of Coastal Aquatic Environments 2005; Editors R.L. Miller et al. Springer (pp 345). 